\title{
An Open-Access, Multi-Decadal, Three-Dimensional, Hydrodynamic Hindcast Dataset for the Long Island Sound and New York/New Jersey Harbor Estuaries
}

\author{
Nickitas Georgas ${ }^{1, *}$, Lun Yin ${ }^{1}$, Yu Jiang ${ }^{1}$, Yifan Wang ${ }^{1}$, Penelope Howell ${ }^{2}$, Vincent Saba ${ }^{3}$, \\ Justin Schulte ${ }^{1}$, Philip Orton ${ }^{1}$ and Bin Wen ${ }^{1}$ \\ 1 Davidson Laboratory, Stevens Institute of Technology, Hoboken, NJ 07030, USA; lyin1@stevens.edu (L.Y.); \\ yjiang14@stevens.edu (Y.J.); ywang152@stevens.edu (Y.W.); jschulte@stevens.edu (J.S.); \\ porton@stevens.edu (P.O.); bwen1@stevens.edu (B.W.) \\ 2 Marine Fisheries Division, Connecticut Department of Energy and Environmental Protection, Old Lyme, \\ CT 06371, USA; Penny.Howell@ct.gov \\ 3 NOAA, National Marine Fisheries Service, Northeast Fisheries Science Center, Geophysical Fluid Dynamics \\ Laboratory, Princeton University, Princeton, NJ 08540, USA; vincent.saba@noaa.gov \\ * Correspondence: nickitas.georgas@stevens.edu; Tel.: +1-201-216-8218
}

Academic Editor: Richard P. Signell

Received: 17 July 2016; Accepted: 11 August 2016; Published: 16 August 2016

\begin{abstract}
This article presents the results and validation of a comprehensive, multi-decadal, hindcast simulation performed using the New York Harbor Observing and Prediction System's (NYHOPS) three-dimensional hydrodynamic model. Meteorological forcing was based on three-hourly gridded data from the North American Regional Reanalysis of the US National Centers for Environmental Prediction. Distributed hydrologic forcing was based on daily United States Geologic Survey records. Offshore boundary conditions for NYHOPS at the Mid-Atlantic Bight shelf break included hourly subtidal water levels from a larger-scale model ran for the same period, tides, and temperature and salinity profiles based on the Simple Ocean Data Assimilation datasets. The NYHOPS model's application to hindcast total water level and 3D water temperature and salinity conditions in its region over three decades was validated against observations from multiple agencies. Average indices of agreement were: 0.93 for storm surge ( $9 \mathrm{~cm}$ RMSE, $90 \%$ of errors less than $15 \mathrm{~cm}), 0.99$ for water temperature $\left(1.1{ }^{\circ} \mathrm{C}\right.$ RMSE, $99 \%$ of errors less than $\left.3{ }^{\circ} \mathrm{C}\right)$, and 0.86 for salinity (1.8 psu RMSE, $96 \%$ of errors less than $3.5 \mathrm{psu}$ ). The model's skill in simulating bottom water temperature, validated against historic data from the Long Island Sound bottom trawl survey, did not drift over the years, a significant and encouraging finding for multi-decadal model applications used to identify climatic trends, such as the warming presented here. However, the validation reveals residual biases in some areas such as small tributaries that receive urban discharges from the NYC drainage network. With regard to the validation of storm surge at coastal stations, both the considerable strengths and remaining limitations of the use of North American Regional Reanalysis (NARR) to force such a model application are discussed.
\end{abstract}

Keywords: Long Island Sound; New York/New Jersey Harbor Estuary; NYHOPS model; multi-decadal hydrodynamic hindcast; North American Regional Reanalysis

\section{Introduction}

Every year since 1976 has had an average global temperature warmer than the long-term average. Over the 1979-2013 period, global temperature warmed at an average of $0.26{ }^{\circ} \mathrm{C}$ per decade over land and $0.10^{\circ} \mathrm{C}$ per decade over the global ocean [1]. The recently signed Paris Agreement [2], adopted by 195 countries, has a long-term goal of keeping the increase in global average temperature to well below 
$2{ }^{\circ} \mathrm{C}$ above pre-industrial levels, and aims to limit the increase to $1.5^{\circ} \mathrm{C}$, as doing so is expected to significantly reduce risks and the impacts of climate change. Yet, the Northeast US shelf waters have experienced higher warming rates than the global ocean, deduced by the Sea Surface Temperature (SST) satellite record. Pershing et al. [3] reported that SST rose by $0.30{ }^{\circ} \mathrm{C}$ per decade between 1982 and 2013 in the Gulf of Maine. The sole long-term observation record for water temperatures within the Long Island Sound (LIS) estuary, a US Estuary of National Significance, at a location near Millstone CT [4] has measured a much more rapid increase in LIS water temperatures than the global average: an alarming $0.44{ }^{\circ} \mathrm{C}$ per decade between 1979 and 2013, over four times higher than the global average rate. Over coastal Connecticut counties, on LIS's northern coast, surface air temperatures for the same time period increased by $0.33^{\circ} \mathrm{C}$ per decade; that rate was double if only the 1992-2012 period was considered, but has decreased somewhat since, to $0.28^{\circ} \mathrm{C}$ per decade (1979-2015; [1]).

Over these last few decades, the LIS ecosystem has undergone profound changes. Ocean warming is suggested to be the most important factor associated with the observed shifts in the mean center of biomass in Northeast U.S. fisheries [3,5-7]. However, understanding what controls the observed trends in the Northeast U.S., and how such processes affect the LIS ecosystem, has been limited due to the paucity of available three-dimensional, physical data. In 2013, the New York and Connecticut Sea Grants and the US EPA Long Island Sound Study joined forces to fund a multi-disciplinary project to address this deficiency, spearheading collaborative research involving numerical modelers, climate scientists, and fishery biologists. The work evaluated conditions and identified warming, freshening, and estuarine circulation trends in Long Island Sound over the past three decades. This research also explored how global climate contributes to long-term and inter-annual variability in the LIS physical environment and its Living Marine Resources [8].

This research article, presented at the 14th Estuarine and Coastal Modeling Conference (ECM14, http://ecm.github.io/ECM14/), focuses on the validation and results of a comprehensive, multi-decadal, hindcast simulation performed using the New York Harbor Observing and Prediction System (NYHOPS) hydrodynamic model that generated a continuous, three-dimensional dataset for a coastal aquatic region that includes Long Island Sound and the New York/New Jersey Harbor (NYNJH) Estuaries, between 1981 and 2013. Section 2 describes the data and methods used to set up the multi-decadal hindcast and the data and methods used to validate it for LIS and NYNJH and to have it serve as an open access dataset. Section 3 presents validation results. Section 4 puts the importance of the validation in perspective and discusses identified or verified trends and climatologies based on the validated model. Conclusions are outlined in the last section. Supplementary material in the form of a comprehensive PowerPoint presentation configured in two parts is also provided.

An online THREDDS Data Server (http://colossus.dl.stevens-tech.edu/thredds/catalog.html) was set up to serve the NYHOPS model's results in oceanographic NetCDF format over the web using the OPENDAP protocol, enabling open access to daily averaged or monthly averaged time series for all the gridded hindcast physical variables in or over the NYHOPS region (including LIS and NYNJH). Simulated climatologies (mean simulated climate conditions averaged over the three decades of the NYHOPS hindcast period) for two- and three-dimensional fields such as water temperatures and salinities, were also generated, and included in THREDDS. The use of the validated results of the model to research global climate teleconnections to the LIS ecosystem and its living marine resources will be presented in subsequent papers that are presently under preparation.

\section{Materials and Methods}

The completed multi-decadal high-resolution three-dimensional hindcast simulation for LIS and NYNJH was based on a nested modeling concept utilizing two hydrodynamic domains (Figure 1): The Stevens North Atlantic Predictions model (SNAP) [9-11] and the New York Harbor Observing and Prediction System model (NYHOPS, www.stevens.edu/NYHOPS) [9,11-18]. Both domains were simulated in 3D with the Stevens Estuarine and Coastal Ocean Model code (sECOM) [11,14,19], a derivative of the Princeton Ocean Model [20]. The SNAP model was run first, in a diagnostic mode 
(clamping temperature and salinity at the initial condition), at its regular $5 \mathrm{~km}$ resolution grid for the complete 1979-2013 simulation. SNAP wave and water level results, along with observation-based temperature and salinity fields, were then used to derive NYHOPS offshore boundary conditions and force the NYHOPS prognostic hindcast simulation on its variable-resolution grid ( $4 \mathrm{~km}$ to $25 \mathrm{~m}$ horizontal resolution, 10 vertical sigma layers). This is the same nesting concept used operationally for the ensemble-based Stevens Flood Advisory System (www.stevens.edu/SFAS [11]).

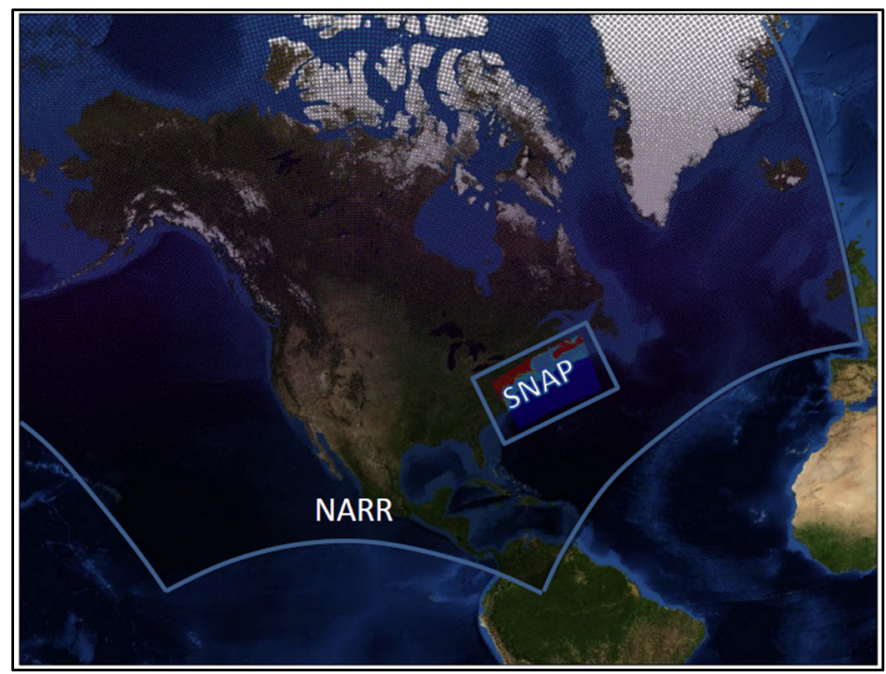

(a)

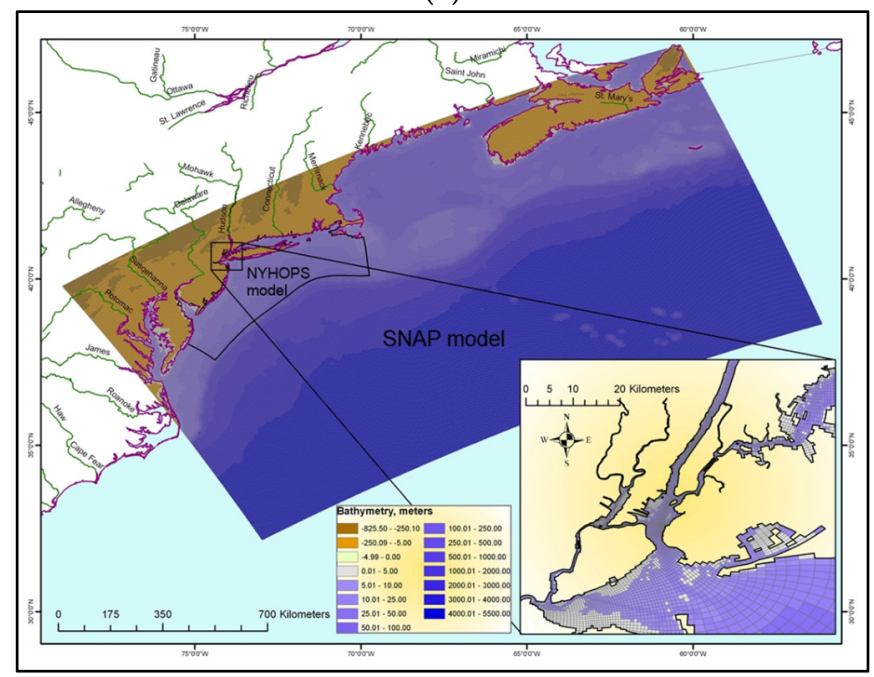

(b)

Figure 1. Hydrodynamic simulation domains used in this work: (a) The Stevens North Atlantic Prediction model (SNAP) domain embedded within the NCEP North-American Regional Reanalysis meteorological model; (b) The New York Harbor Observing and Prediction System model (NYHOPS) domain, embedded within the SNAP model domain. The insert highlights NYHOPS variable grid resolution in the NYNJH and Western LIS. Colors show bathymetry, in meters.

Surface meteorological forcing to both SNAP and NYHOPS was based on gridded data from the North American Regional Reanalysis (NARR [21]) created for the US National Centers for Environmental Prediction (NCEP). NARR (Figure 1) has been shown to have good skill for regional climate studies [22], but may be deficient for strong Atlantic precipitation events and Atlantic hurricanes [21]. Three-hourly surface meteorological variables provided by NARR at its $32 \mathrm{~km}$ grid were interpolated to the SNAP and NYHOPS grids and used to force the two models throughout 
the hindcast. Winds at $10 \mathrm{~m}$ above surface and barometric pressure reduced to mean sea level, total cloud cover, relative humidity and air temperature at $2 \mathrm{~m}$ above ground were used to compute locally dynamic surface heat flux terms, surface stress terms and surface wave growth terms with the methodology described in [14] and [23] as progressed by Orton et al. [17] based on internally calculated surface wave fields and explicit wave-steepness by Taylor and Yelland [24].

In the construction of the three dimensional NYHOPS hindcast, great care was put into creating high-fidelity lateral and internal boundary conditions for hydrodynamic forces included in the NYHOPS model, to complement the surface meteorological forcing provided by NARR. SNAP model results were used to provide hourly offshore boundary conditions to NYHOPS at the Mid-Atlantic Bight shelf break for surface waves and offshore tidal residuals (storm surge), the latter being used to provide the subtidal part to the tidal NYHOPS water level boundary conditions as in $[14,15]$. An attempt was made to account for steric and mean sea level rates across the NYHOPS simulations by adding the spatially and-seasonally averaged residual errors across SNAP coastal station predictions within the NYHOPS domain to the NYHOPS offshore water level boundary conditions $[14,15]$; average rates are listed in [25]. The observed water level records used in this step were tied to the geodetic NAVD88 datum.

Further, to provide offshore temperature and salinity profiles at the continental shelf break to NYHOPS for the hindcast, monthly data from the Simple Ocean Data Assimilation (SODA) climatology for water temperature $(T)$ and salinity $(S)$ were acquired beginning in 1959 on a global 0.5 degree geographic resolution grid with 40 standard depth levels in the vertical [26]. Some issues were identified with the continuity and versioning of the available SODA datasets that required significant effort in order to create a consistent monthly climatological dataset for the complete NYHOPS hindcast period of 1979-2013. A unified set of NYHOPS boundary conditions was created using SODA version 2.1.6 from 1979-1999, then SODA version 2.2.4 from 2000-2010, then results from a ROMS model run [18] generated at Rutgers University nested within a global HYCOM model for 2011-2012, and finally HYCOM global model results for 2013 [27]. To decrease climatologically relevant discrepancies between the last two datasets and SODA, bias correction for the last two datasets was performed both for the T/S means and their range. The native ROMS results for 2011-2012 were bias-corrected based on mean and range anomalies between the SODA version 2.2.4 datasets and the ROMS-with-HYCOM datasets for the common years of 2005-2008. HYCOM for 2013 was similarly bias-corrected based on the same debiasing factors. The assumption was that if the ROMS and HYCOM models were biased compared to SODA years 2005-2008 (shifted and inflated/deflated), they would continue being biased in a similar fashion in subsequent years. This assumption was validated by comparing the debiased datasets against SODA 2.2.4 for the last two SODA years, 2009-2010. Both means and ranges were significantly closer to SODA after debiasing (not shown). After the unified monthly $T / S$ dataset from 1979 to 2013 was created at SODA resolution, it was interpolated in space and time along the NYHOPS offshore boundary, checked for vertical density stability, and used to force the NYHOPS 3D hindcast simulation.

Distributed hydrologic forcing to the NYHOPS estuarine model was based on daily United States Geologic Survey (USGS) records [25] with comparable but expanded results to other regional published studies [28,29]. As part of this work, a fluvial temperature study for rivers with long temperature time series across the Mid-Atlantic was completed to aid with the assignment of daily temperatures to riverine discharges in the NYHOPS hindcast (NYHOPS includes an extensive hydrologic input network [14]). That work was presented at the annual Mid-Atlantic Bight Oceanography and Meteorology Meeting (MABPOM 2013). Results indicated that river temperatures, and associated thermal inputs to Mid-Atlantic waters increased-similarly to, though somewhat less rapidly than, the regional air temperature trends-with variation in the positive rate values between different MAB watersheds (Figure 2). River flows also increased considering the 1979-2013 period as a whole. Based on linear trends estimated from the USGS discharge data, major freshwater river inflow rates to the LIS and NYNJH increased significantly: the Connecticut River at Thompsonville (USGS station 
ID 01184000 ) by $17 \%$ - the Connecticut River contributes about $75 \%$ of total freshwater flow into LIS-the Housatonic River at Stevenson (USGS station ID 01205500) by 21\%, and the Hudson River at Green Island by 33\% (USGS station ID 01358000). The completed daily time series of estimated river flows and temperatures from 1979 to 2013 were used as distributed discharge forcing in the NYHOPS 3D hindcast. Ungauged tributaries in NYHOPS are included through basin-area scaling of observed hydrographs from proximal gauged rivers. Finally, distributed end-of-pipe Point Source forcing is also included in NYHOPS model runs based on monthly climatologies of waste water treatment plant effluent and power plant intake/outfall pairs [14].

The model hindcast simulation period started in 1979 and completed in 2013. The first two years were considered spin-up years for 3D hydrodynamics. Therefore, for consistency, results will be presented from $1981 \mathrm{on}$. This hypothesis was tested in LIS by considering different initial conditions updated every five years from the hindcast. It was found that the NYHOPS solution for $T$ and $S$ within the LIS estuary would converge well within two years from initiation.
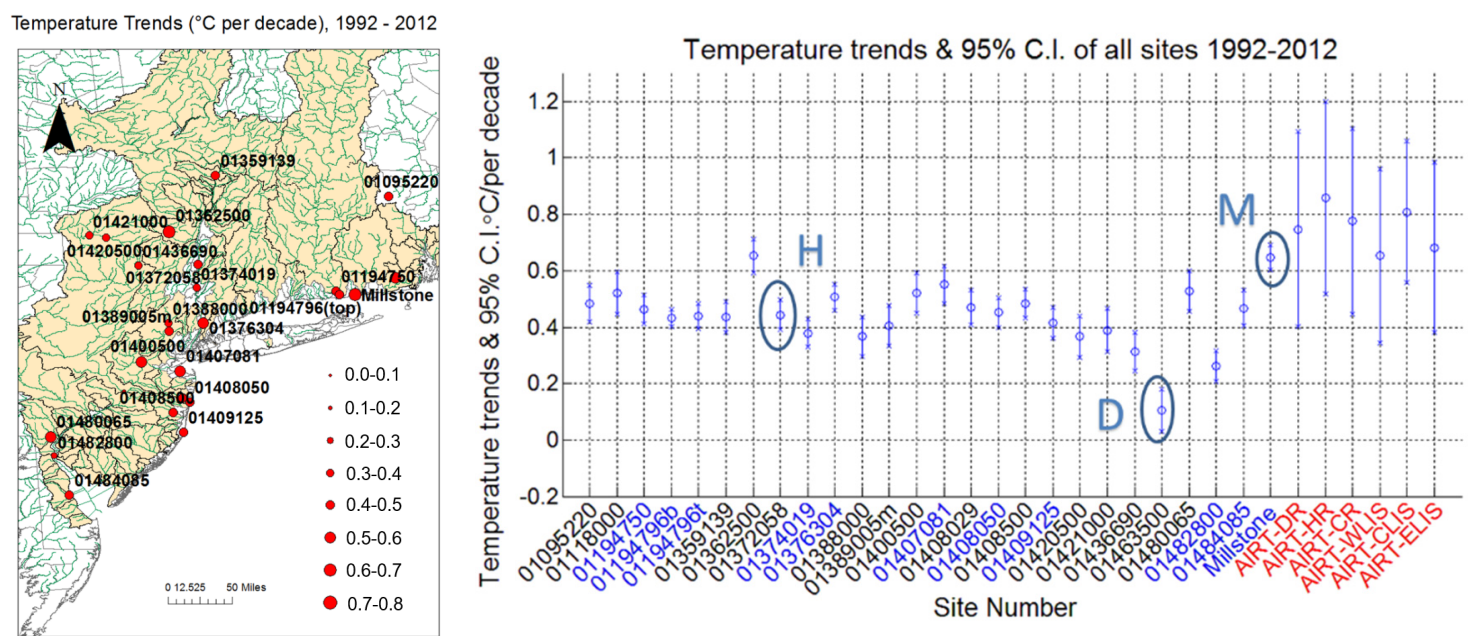

Figure 2. Linear temperature trends $\left({ }^{\circ} \mathrm{C}\right.$ per decade) for different NYHOPS river stations between 1992 and 2012 shown in the Mid-Atlantic Region map. The trend over the same time period at the LIS basin near Millstone, CT is also shown for comparison ("M" in the insert to the right). Also highlighted are the Hudson River at Poughkeepsie (" $\mathrm{H}^{\prime \prime}$ ) and the Delaware River at Trenton, NJ ("D"). Monthly NARR-based, watershed-area-averaged, surface air temperature linear trends are also included in the right panel as "AIRT- $w$ " where watershed $w \in$ [DR, HR, CR, WLIS, CLIS, ELIS] = [Delaware River, Hudson River, Connecticut River, Western LIS, Central LIS, Eastern LIS]. 95\% confidence intervals are included as vertical bars, with central estimates shown as circles.

The NYHOPS model's application to hindcast total water level, and 3D water temperature and salinity conditions in its region over three decades was validated extensively against various available observational datasets. Hourly total water levels collected by the National Ocean Service (NOS) at 12 coastal stations within the NYHOPS domain between 1979 and 2013 were used to quantify the model's performance to storm surge after subtraction of the NOS-predicted astronomical tide (Figure 3a). Near-surface and near-bottom $T$ and $S$ grab samples taken with variable frequency-weekly to biweekly, and mostly during summer-from a New York City Department of Environmental Protection (NYC DEP) boat between 1981 and 2012 were used to quantify the skill of the model for $T$ and $S$ at NYC DEP stations in NYNJH (Figure $3 b$ ). Vertical CTD casts from cruise surveys conducted for the Long Island Sound Study between 1991 and 2012 as provided by the Connecticut Department of Energy and Environmental Protection (CT DEEP) were used to quantify the skill of the model for $T$ and $S$ in LIS (Figure 3c). Near-bottom temperatures collected on a regular grid that covers most of the LIS bottom by CT DEEP fisheries as part of the Long Island Sound Trawl Survey between 1992 and 2013 were used to test whether the model's skill in simulating bottom water temperature showed signs of drift over 
the years in LIS (Figure 3d). Finally, an observations-based monthly three-dimensional temperature and salinity climatology dataset called MOCHA version-2 created at Rutgers University in New Jersey (http://tds.marine.rutgers.edu/thredds/catalog/other/climatology/mocha/catalog.html; [30] as updated in MOCHA's 2nd version in 2012) was used to quantify the skill of the NYHOPS hydrodynamic model for $T$ and $S$ against climatology. MOCHA is a three-dimensional climatological analysis of the temperature and salinity, with a 0.05 degree $(\sim 5 \mathrm{~km})$ grid in the horizontal and 55 standard depths in the vertical that covers the $\mathrm{MAB}$, from $45^{\circ} \mathrm{N}$ to $32^{\circ} \mathrm{N}, 77^{\circ} \mathrm{W}$ to $64^{\circ} \mathrm{W}$. It is derived from all in situ data available from the NODC World Ocean Database 2005 and the NOAA North East Fisheries Science Center database. Comparisons to MOCHA were only made in LIS as the NYNJH is not well resolved in its grid.

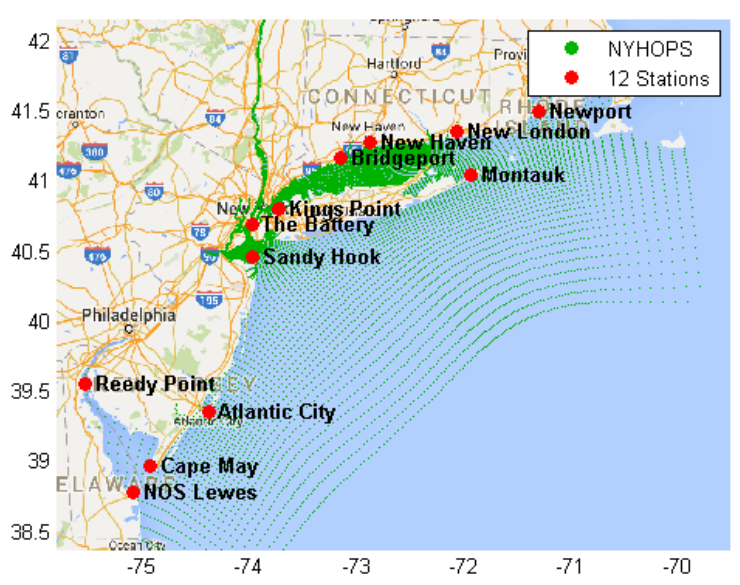

(a)

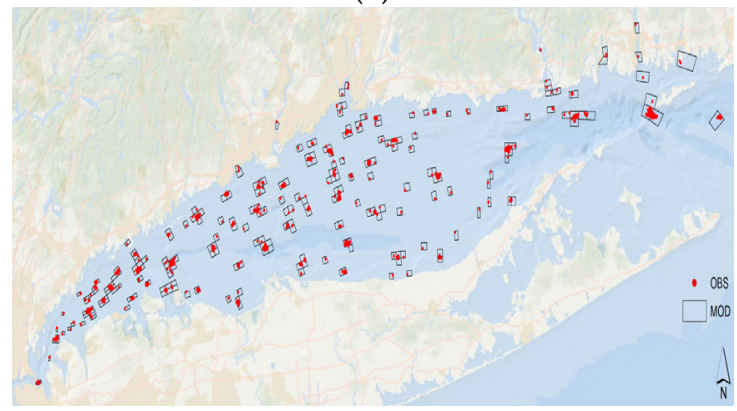

(c)

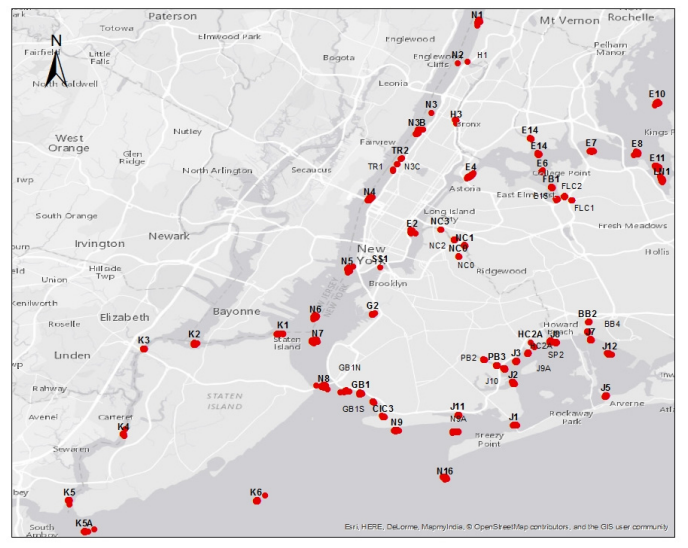

(b)

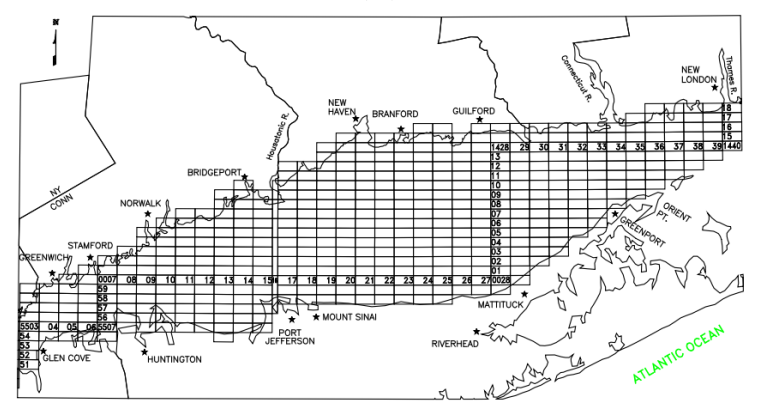

(d)

Figure 3. Observations used to validate the model in this study. (a) 12 NOS coastal stations; (b) NYC DEP Harbor Survey stations throughout the years; (c) Long Island Sound Study cruise stations through the years; (d) Long Island Trawl Survey Site grid.

Adopting NOS guidelines and prior literature used for validating the operational NYHOPS forecast model $[11,15,16,31]$, the following metrics were used to quantify model skill in the Results section:

- $\quad$ Bias or mean error, M.E.: The mean error between model and observations.

- RMSE: The square root of the average error between model and observations squared.

- $\quad$ R-square, $R^{2}$ : The square of the correlation coefficient between model and observations.

- Willmott Skill or Index of Agreement, W.I. [32]: A non-dimensional measure of how close the model's results are to observations. Values are between 0 and 1 , with 1 being a perfect "skill core."

- Central frequency of error, C.F.: The percent of errors that are below a given threshold that is considered high for operational use. The larger the C.F., the better the model. NOS usually 
considers a C.F. $\geq 90 \%$ as accepted model performance against the following thresholds: $15 \mathrm{~cm}$ for total water level, $3.0^{\circ} \mathrm{C}$ for $T$, and 3.5 psu for $S$ [31].

- Taylor diagram, [33]. The Taylor Diagram provides a visual statistical summary of how well the model and observation patterns match each other in terms of their correlation coefficient $(R)$, their root mean square error (RMSE), and their standard deviation ( $\sigma)$.

- Brier Skill Score, B.S.S. [34]: The Brier Skill Score essentially compares the magnitude of the difference between a model (NYHOPS here) and observations to that achieved by a reference model (the monthly MOCHA climatology here). The B.S.S. is written as

$$
B S S=1-\frac{1}{N_{i}} \sum_{j=1}^{N_{i}}\left(d_{i, j}-p_{i, j}\right)^{2} / \frac{1}{N_{i}} \sum_{j=1}^{N_{i}}\left(d_{i, j}-r_{i, j}\right)^{2}
$$

where the vector $d_{i, j}$ contains the $j=1,2, \ldots, N_{j}$ measurements (in situ observations). Similarly, $p_{i, j}$ are the model predictions at the same time and location of the data, $d_{i, j}$, and the vector $r_{i, j}$ contains the predictions of the reference climatology (MOCHA here). BSS compares the ratio of the variance in the observations not explained by the model to that not explained by the reference climatology. If $B S S>0$, then the model is in better agreement with the data than the reference model. Conversely, if $B S S<0$, it is not as good.

NYHOPS model results were interpolated from the native NYHOPS grid to the location and time of individual observations, before making comparisons. It is important to note that there are always discrepancies in the observations due not only to the precision of the instruments and analyses methods, but also due to the difference in the property simulated (the average over a model cell's volume and output time step) and that measured (sometimes a few samples from a bottle). Even a perfect model, therefore, should not be expected to have BSS $=1$, (nor will W.I. and $R^{2}$ be equal to unity for that matter). Given however the comparison to average climatology, BSS for a skillful model should be consistently higher than 0 , and hopefully closer to unity. Finally, binned histograms of model errors against observations were also used to show uncertainty in model results, and whether that uncertainty grew or decreased over the hindcast years.

\section{Results}

The model's grand-mean temperature and salinity bias against all Long Island Sound Study observations in the Sound was found to be $0.18^{\circ} \mathrm{C}$ warmer for water temperature, and $1.31 \mathrm{psu}$ saltier for salinity; these biases were assumed constant in time and space and were removed from all raw NYHOPS model gridded time series results. The local tidal correction procedure described in [16] was applied to the raw NYHOPS water level results for the 12 coastal stations. The astronomical tide predicted by NOS at these stations was used in that correction, and then removed from the total water level signals to calculate storm surge. The results used and shown below are after these treatments were put into effect.

\subsection{Storm Surge Validation}

Figure 4 shows example storm surge results at The Battery, NY, highlighting the storm surge validation that was performed at each of the 12 NOS stations. The highest storm surge (SS) and total water level (TWL) values at The Battery for the 1981-2013 time period shown were simulated by NYHOPS to have occurred during Hurricane Sandy in 2012. Although this is consistent with the observed record, the NARR-forced NYHOPS hindcast under-predicted surge during that storm by about 2 feet or $\sim 20 \%$.

Table 1 lists NYHOPS hindcast performance metrics for TWL and SS using the methods of Georgas and Blumberg [15] against NOS observations at 12 coastal stations. RMSE varied between $5.7 \mathrm{~cm}$ at Montauk, NY and $14.1 \mathrm{~cm}$ at Reedy Point, DE, the latter being in a region (Delaware Bay) not well 
resolved by the NYHOPS model's horizontal grid. $R^{2}$ for TWL that includes astronomical tide varied between 0.95 at Montauk and 0.99 at New Haven, Kings Point, and Bridgeport where the tide range is larger. Excluding astronomical tide, $R^{2}$ for SS was lowest where RMSE was highest. In addition to Delaware Bay, this relative degradation in storm surge prediction occurred in west-central LIS at Bridgeport and Kings Point. As expected, W.I. and $R^{2}$ for SS were positively correlated and showed similar qualitative results. W.I. for TWL was higher than 0.98 everywhere (not shown). Similar to the operational NYHOPS forecast validation [16], 8 out of the 12 stations had C.F. $<15 \mathrm{~cm}$ over $90 \%$, with one more (The Battery, NY) coming also very close at $89.9 \%$. Overall the results of the NYHOPS hindcast for water level and its storm surge component were good, providing confidence that the model was able to reproduce hydrodynamics reasonably well.
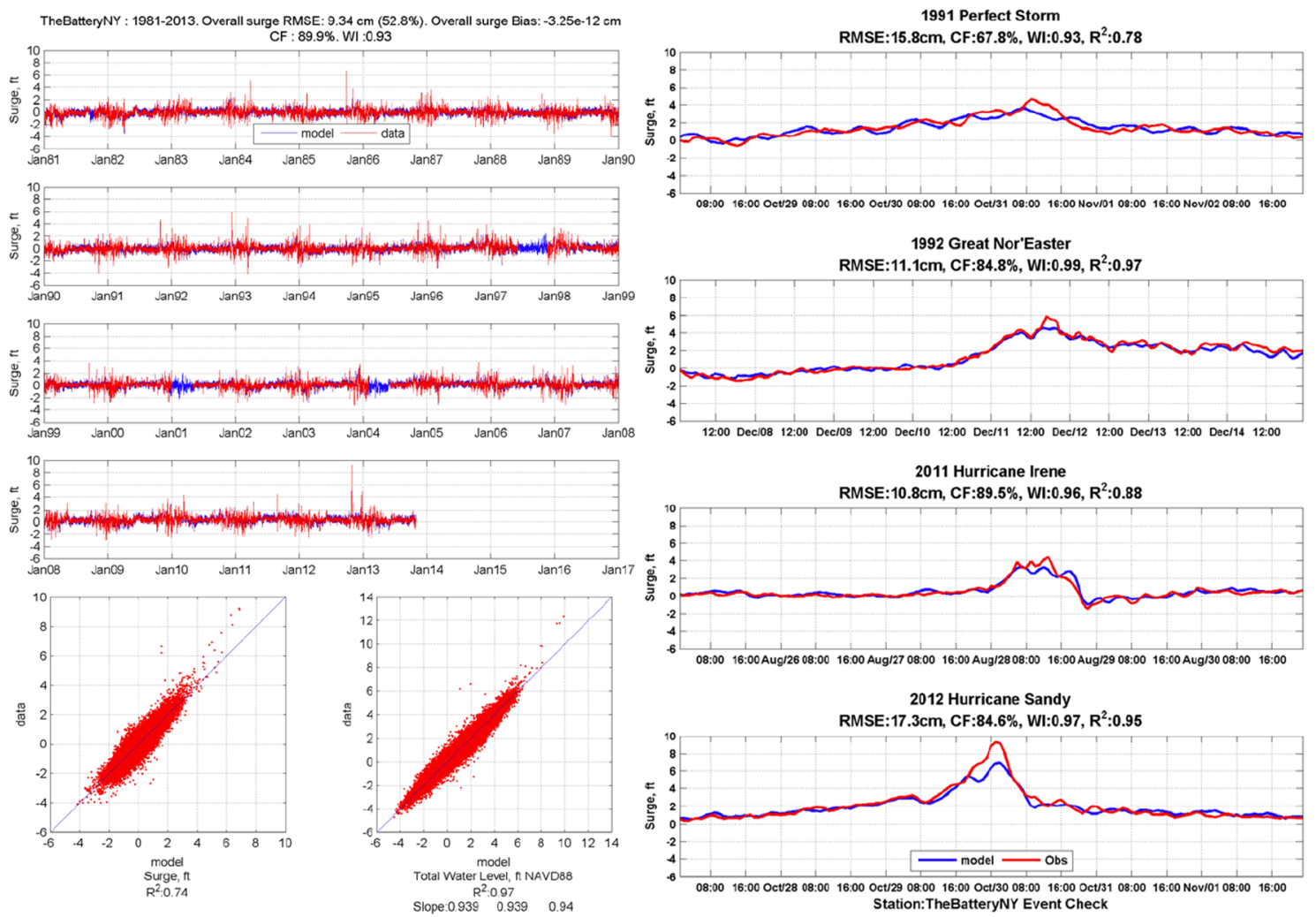

2012 Hurricane Sandy

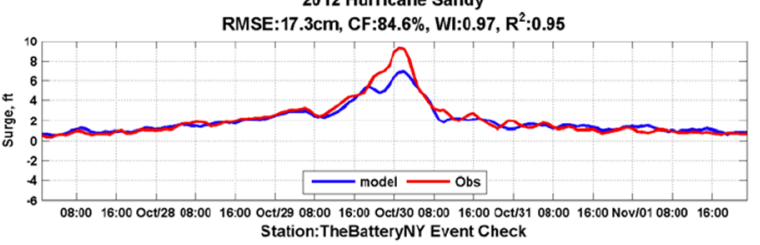

Figure 4. Observed (red) and NYHOPS-simulated (blue) SS (=TWL-astronomical tide) time series for the complete 1981-2013 series (left), as well as four regionally significant events. Correlograms, and their statistics, for both SS and TWL within the complete 1981-2013 period, are also shown on the bottom left.

Table 1. NYHOPS hindcast performance metrics for total water level (TWL) and storm surge (SS) at 12 NOS stations.

\begin{tabular}{ccccccc}
\hline Station Name & Dates & RMSE, $\mathbf{c m}$ & $\boldsymbol{C F} \leq \mathbf{1 5} \mathbf{~ c m}, \mathbf{\%}$ & $\boldsymbol{R}^{\mathbf{2}} \mathbf{S S}$ & $\boldsymbol{R}^{\mathbf{2}}$ TWL & $\boldsymbol{W I}_{\mathbf{S S}}$ \\
\hline Lewes, DE & $1979-2012$ & 8.6 & 91.9 & 0.78 & 0.97 & 0.94 \\
Reedy Point, DE & $1996-2013$ & 14.1 & 71.7 & 0.63 & 0.96 & 0.88 \\
Cape May, NJ & $1979-2013$ & 7.8 & 94.6 & 0.80 & 0.98 & 0.95 \\
Atlantic City, NJ & $1985-2013$ & 6.6 & 97.2 & 0.86 & 0.98 & 0.96 \\
Sandy Hook, NJ & $1979-2013$ & 9.0 & 91.1 & 0.76 & 0.97 & 0.93 \\
The Battery, NY & $1979-2013$ & 9.3 & 89.9 & 0.74 & 0.97 & 0.93 \\
Kings Point, CT & $1998-2013$ & 12.8 & 76.4 & 0.65 & 0.99 & 0.90 \\
Bridgeport, CT & $1996-2013$ & 11.6 & 79.8 & 0.65 & 0.98 & 0.89 \\
\hline
\end{tabular}


Table 1. Cont.

\begin{tabular}{ccccccc}
\hline Station Name & Dates & RMSE, $\mathbf{c m}$ & $\boldsymbol{C F} \leq \mathbf{1 5} \mathbf{~ c m}, \mathbf{\%}$ & $\boldsymbol{R}^{\mathbf{2}} \mathbf{S S}$ & $\boldsymbol{R}^{\mathbf{2}}$ TWL & $\boldsymbol{W I}_{\mathbf{S S}}$ \\
\hline New Haven, CT & $1999-2013$ & 9.1 & 90.6 & 0.75 & 0.99 & 0.93 \\
Montauk, NY & $1979-2013$ & 5.7 & 98.9 & 0.85 & 0.95 & 0.96 \\
New London, CT & $1979-2013$ & 7.1 & 96.5 & 0.78 & 0.96 & 0.94 \\
Newport, RI & $1979-2013$ & 7.4 & 95.6 & 0.72 & 0.97 & 0.92 \\
\hline
\end{tabular}

\subsection{Water Temperature and Salinity Validation}

3.2.1. Against New York City Department of Environmental Protection (NYC DEP) Data in the New York/New Jersey Harbor (NYNJH) Estuary

The correlograms shown in the top row of Figure 5 summarize the comparison of the NYHOPS hindcast results against all observations for T and S taken by NYC DEP between 1981 and 2012 at the surface and bottom of the NYNJH at all Harbor Survey stations. For water temperatures, most points fell along the 1:1 line. Although this was also true for $\mathrm{S}$, there were several observations that were not well-captured by the model, with most of these values being over-predicted by the model. Thorough station-by-station and event-by-event study, summarized in the Discussion section and in the Supplementary Material, revealed that these discrepancies are mostly associated with sewer overflow events and other wet-weather non-point source contributions at small tidal tributaries. Nevertheless, considering the whole estuary and NYC DEP dataset, M.E. was only $-0.1{ }^{\circ} \mathrm{C}$ for $T$ and 0.0 psu for $S$, RMSE was $1.2^{\circ} \mathrm{C}$ for $T$ and 2.3 psu for S, W.I. was 0.99 for $T$ and 0.95 for $S$, while the central frequency of error was as high as $99 \%$ for $T$ and $93 \%$ for $S$, revealing a very skillful hindcast. The Taylor Diagrams on the bottom row of Figure 5 further show that correlation coefficients were higher than 0.9 for both $T$ and $S$, and reveal that the model was able to capture the range of variation both for $T$ and $S$ as shown by the concentric dotted black circles of standard deviation on the diagram. Further, the model's error standard deviation, approximated by the RMSE (also depicted with the green circles in the Taylor Diagram), was overall smaller than the standard deviation of the signal it simulated.

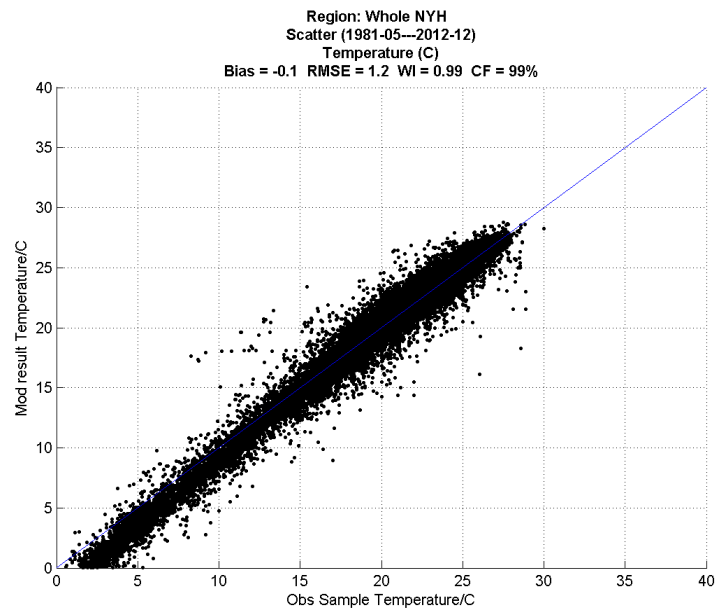

(a)

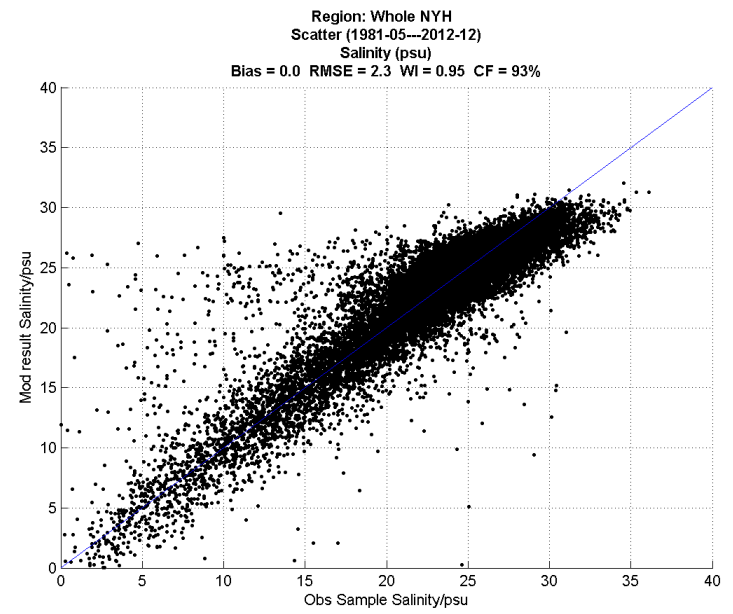

(b)

Figure 5. Cont. 


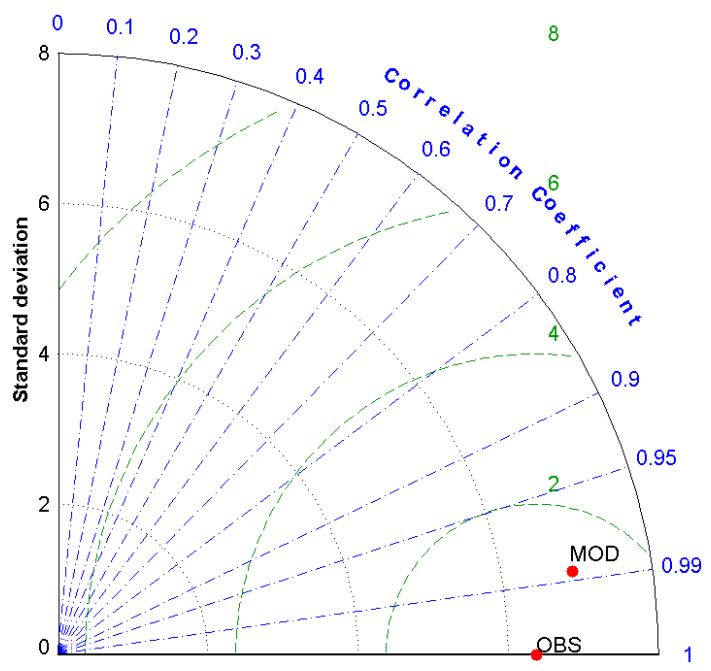

(c)

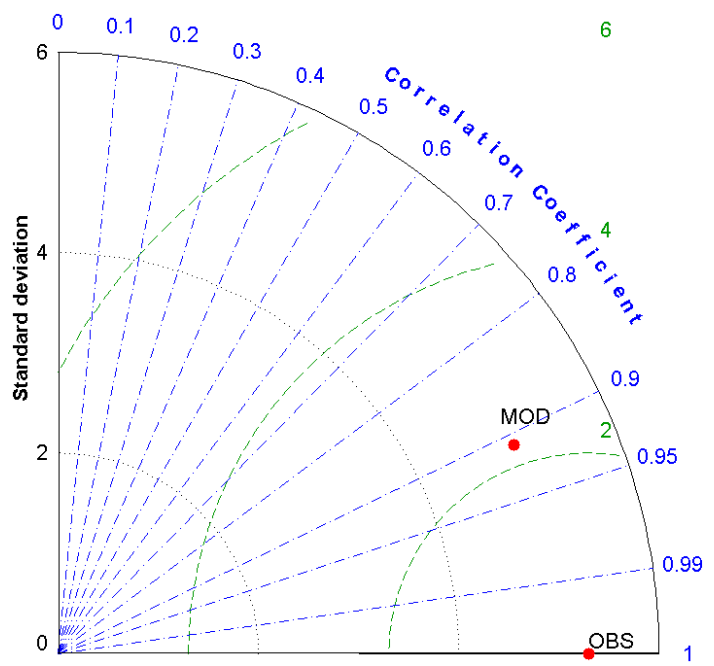

(d)

Figure 5. Correlograms ( $\mathbf{a}$ and $\mathbf{b}$ ), and Taylor Diagrams (c and $\mathbf{d}$ ), summarizing the comparison between the NYHOPS results and NYC DEP Harbor Survey observations for T $(\mathbf{a}, \mathbf{c})$ and S $(\mathbf{b}, \mathbf{d})$. The Taylor Diagrams summarize RMSE (dotted green circles with the observations "OBS" as origin), correlation coefficient (dotted blue radials with 0 origin), and standard deviation (black dotted circles with 0 origin).

Figure 6 shows example time series for simulated surface and bottom $T$ and $S$ against observed surface and bottom $T$ and $S$ at Harbor Survey station N5, the station nearest to The Battery, NY. The model is seen to capture well the ranges and seasonal signals in both $\mathrm{T}$ and $\mathrm{S}$ and shows good skill in responding to events in the record. Surface measurements taken at station N5 in the early 1980s, mid-1990s, and 2002, revealed somewhat higher salinities during peak ocean salt intrusion summer seasons than those simulated by the model. Higher salinities were also observed but not simulated in 2002 near the bottom at station N5.
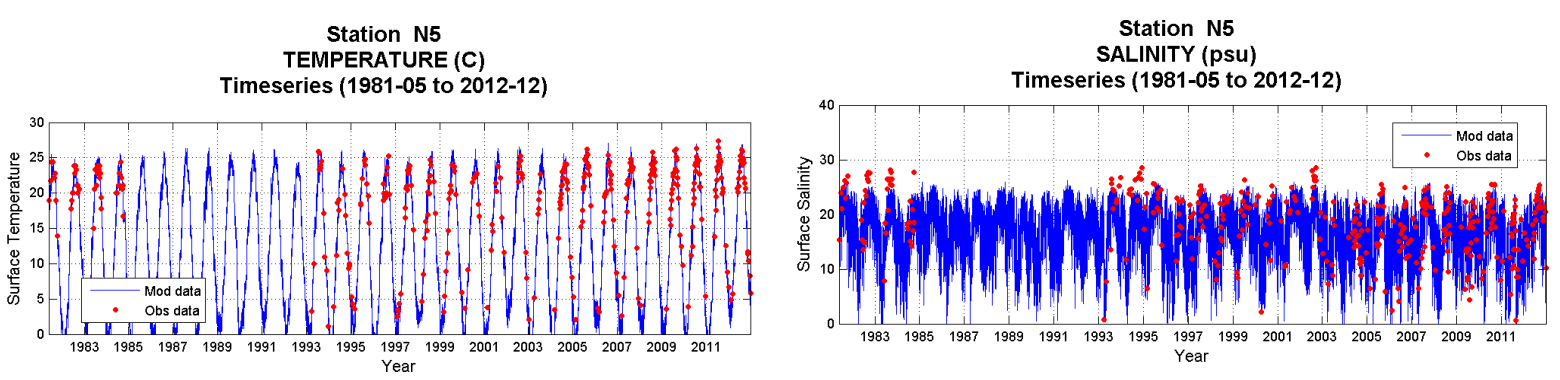

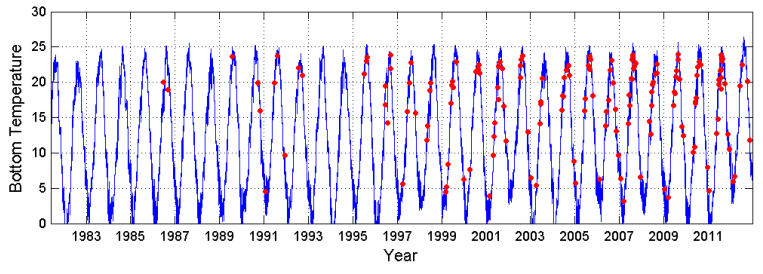

(a)

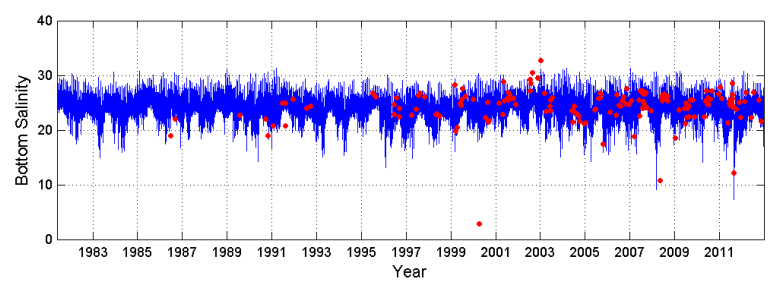

(b)

Figure 6. Time series of observer (red) and simulated (blue) $T$ (a) and $S$ (b) at NYC DEP Harbor Survey station N5 near The Battery, NY. 
3.2.2. Against Connecticut Department of Energy and Environmental Protection (CT DEEP) Data in Long Island Sound (LIS)

Figure 7 shows correlograms summarizing the comparison of the NYHOPS hindcast results against all CTD casts during CT DEEP Long Island Sound Study cruises between 2001 and 2012. Results are summarized by LIS management basin. Most points fell along the 1:1 line, and the model results throughout LIS were overall reasonable. For T, RMSE was close to $1{ }^{\circ} \mathrm{C}$ in all three basins, W.I. was greater than 0.99 , and model errors were less than $3{ }^{\circ} \mathrm{C}$ over $99 \%$ of the time (C.F. $\geq 99 \%$, Figure 7). Salinity RMSE was $0.5 \mathrm{psu}$ in the western and central management basins, but reached $1.0 \mathrm{psu}$ in the eastern basin, largely because of a residual M.E. contribution there of $0.6 \mathrm{psu}$ that was not found for the other two basins. Although the central frequency was greater than $99 \%$ for salinity in all three basins, the W.I. was significantly lower in the eastern basin too, at 0.77 . It appears that the removal of the grand-mean bias of 1.31 psu from all raw NYHOPS hindcast results made the eastern basin of LIS slightly fresher than it should. This result will be discussed further in the Discussion section.

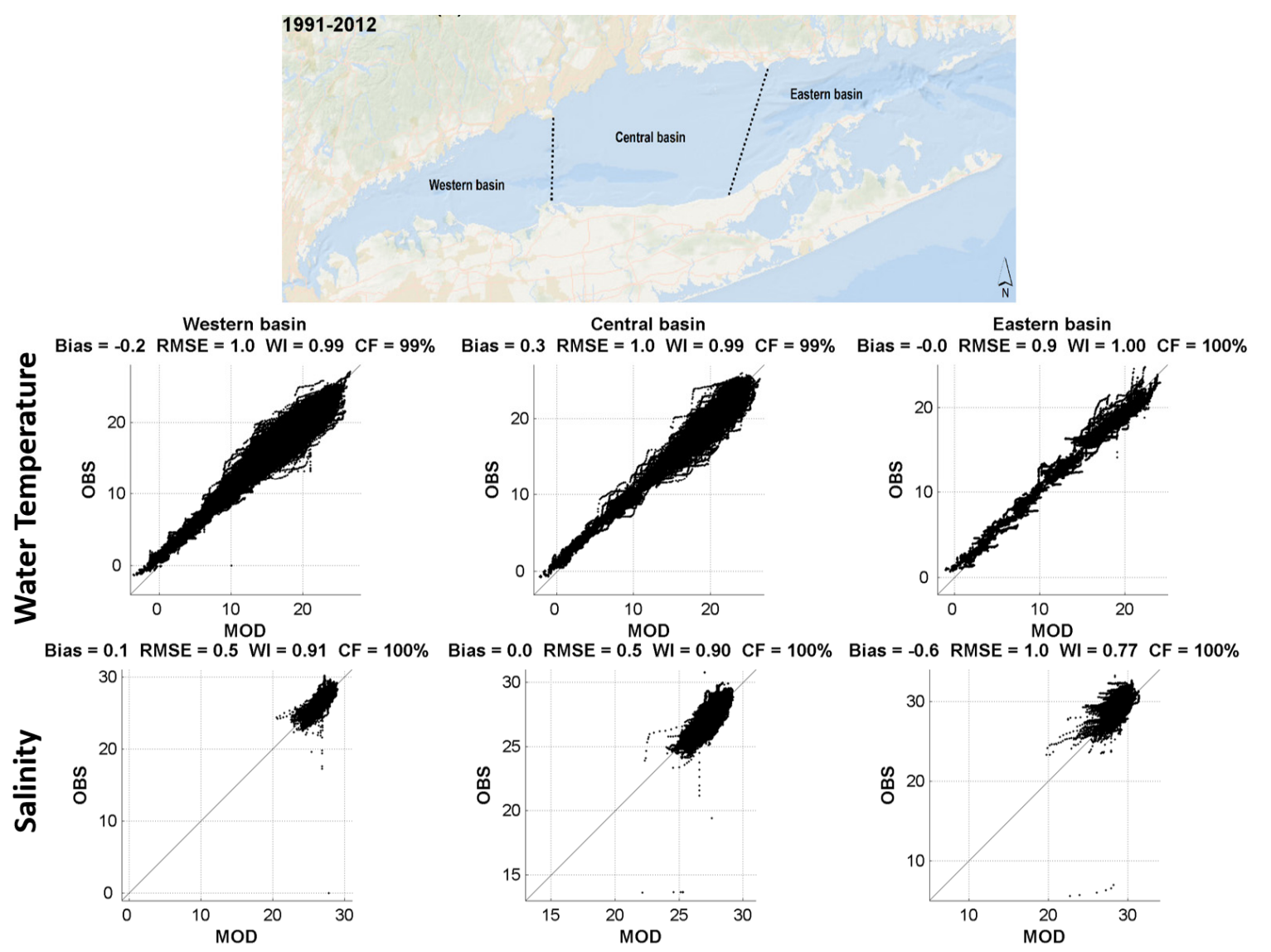

Figure 7. Correlograms, summarizing the comparison between the NYHOPS results and all CT DEEP Long Island Sound Study observations taken between 1991 and 2012 for $T$ and $S$ at the three LIS management basins.

\subsubsection{Against MOCHA Climatology in LIS}

Figure 8 compares the NYHOPS model's performance to hindcast LISS water temperatures and salinities against MOCHA monthly climatology. The top panels of the Figure compare overall performance throughout the LISS record using Taylor Diagrams, while year-to-year relative performance between 1991 and 2012 is depicted in the lower panel as a B.S.S. time series.

The Taylor diagrams show that the NYHOPS model ("M") is closer to the observed conditions $($ " $\mathrm{O}$ ") compared to the MOCHA climatology ("C") for the correlation coefficient and the RMSE 
(Figure 8). Thus the dynamic model exhibits significantly higher correlation and lower error in describing the data. Note that the correlation coefficient scale is logarithmic and that the correlation between the NYHOPS model and the observations is significantly higher especially for salinity where it grew from less than $0.7(\mathrm{C})$ to over $0.9(\mathrm{M})$. The standard deviation captured by the observation-based monthly MOCHA climatology appears closer to the one based on LISS observations than the NYHOPS model, consistently with the Taylor Diagrams for NY Harbor (Figure 5): In both the NYNJH and LIS, the model seems to somewhat over-predict the overall observed range in water temperature and under-predict the overall range in salinity. Even so, the NYHOPS model was overall significantly closer to observations that the climatology: the Taylor dot for the model (M) is closer to the Taylor dot for observations (O) than the Taylor dot for MOCHA climatology (C).

TEMPERATURE (C)
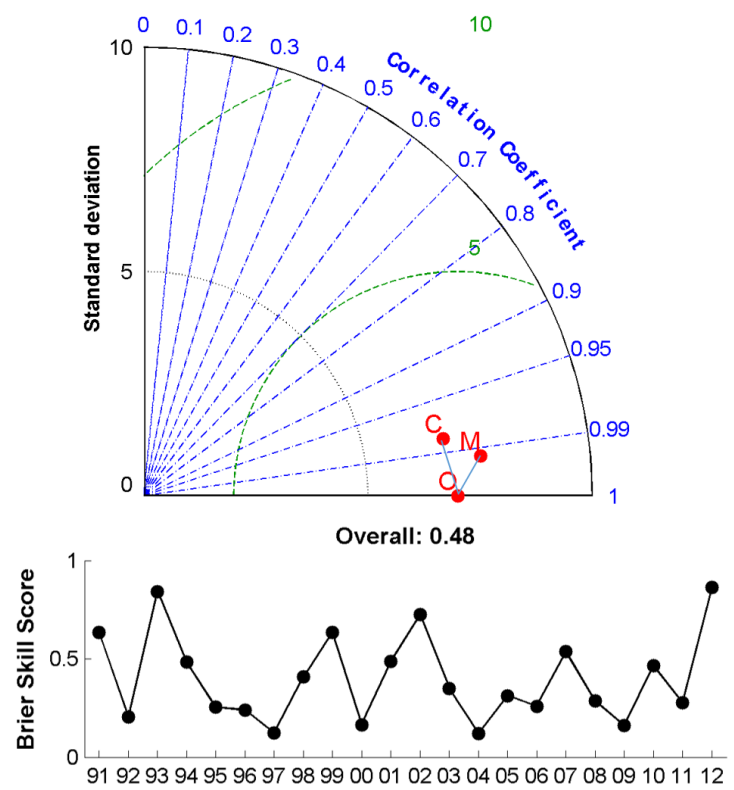

(a)

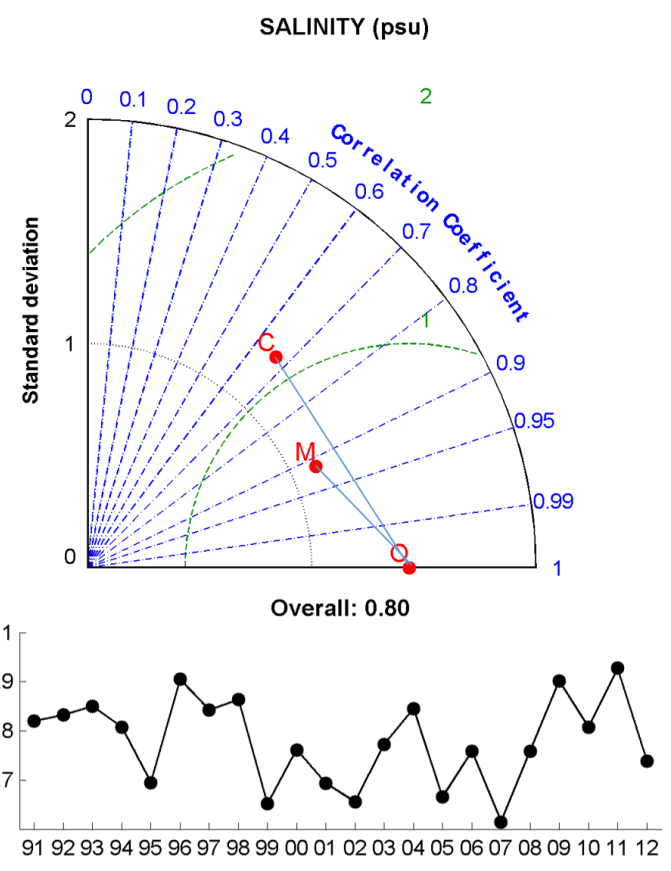

(b)

Figure 8. Taylor Diagrams and time series of B.S.S., comparing the skill of the NYHOPS hydrodynamic model (M) to the climatological MOCHA model (C) in describing CT DEEP Long Island Sound Study observations (O) taken between 1991 and 2012 for $T$ (a) and S (b) in LIS. Taylor Diagrams summarize RMSE (dotted green circles with the observations "O" as origin), correlation coefficient (dotted blue radials with 0 origin), and standard deviation (black dotted circles with 0 origin).

The lower panels in Figure 8 also show that the hydrodynamic NYHOPS model was a better predictor of the year-to-year water temperature and salinity observed in LIS than the static observation-based MOCHA climatology: During the whole LISS observation record from 1991 to 2012, the relative B.S.S. was always higher than 0, meaning NYHOPS had better skill than climatology each year. Peaks close to the optimal 1.0 value in relative BSS are seen in some years that were anomalously cold or hot compared to climatology, such as during 1993 and 2012, respectively. During these years the monthly mean MOCHA climatology would not have been a good descriptor of what happened in LIS, unlike the NYHOPS model that included three-hourly heat flux forcing based on NARR. Given the large seasonal signal in temperature causing higher correlation coefficients even between MOCHA climatology and observations, the relative B.S.S. for water temperature ranged more from year to year than the one for salinity, as seen in the smaller $y$-axis for salinity B.S.S. (Figure 8). Similarly, the 1991-2012 mean B.S.S. for water temperature (0.48) was also smaller than the one for salinity $(0.80)$. For salinity, the B.S.S. ranged largely between 0.6 and 0.9 , since the NYHOPS hydrodynamic model that included daily freshwater flows was, as expected, much more able to reproduce spatiotemporal salinity 
variations compared to the monthly climatological means of MOCHA. No statistically significant trend was found for either water temperature or salinity B.S.S. time series.

\section{Discussion}

The skill of the comprehensively-forced multi-decadal NYHOPS Hindcast presented in the previous paragraph was overall excellent: across all stations considered, the average Willmott Index of Agreement for storm surge (tidal departure) alone against NOS hourly observations was 0.93, (9 cm Root-Mean-Square-Error, RMSE, 90\% of errors less than $15 \mathrm{~cm}$ ). For water temperature against available NYC DEP and CTDEEP observations, W.I. was $0.99\left(1.1^{\circ} \mathrm{C}\right.$ RMSE, $99 \%$ of errors less than $3{ }^{\circ} \mathrm{C}$ ). For salinity against NYC DEP and CTDEEP observations, W.I. was 0.86 (1.8 psu RMSE, 96\% of all errors less than $3.5 \mathrm{psu}$ ).

For water levels, model results were reasonable overall, though model errors against hourly observations increased as expected during major storm surge events and Atlantic hurricanes (Figure 9); Figure 9 can also be compared to [16] (Figure 7) and [11] (Figure 5). This error increase with surge magnitude is in part due to the resolution in time (3-hourly) and space (36 km) of the NARR dataset used to provide winds and barometric pressure to the NYHOPS model. Mesinger et al. in 2006 [21] stated expectations for relatively poorer NARR skill during Atlantic Hurricanes. This may in part be due to a presumed increase of the number of observations fed into NARR during the reanalysis process in later years compared to the beginning of the NARR record in 1979. Storm surges during some early events, the Nor'Easter of March 1984 and Hurricane Gloria in 1985 being examples, were under-predicted. The storm surge from the quick transit of Hurricane Bob that devastated New England in 1991 was also not captured. For example, the surge built from 0 to over 5 feet in $4 \mathrm{~h}$ at Newport, RI, but the 3-hourly, $36 \mathrm{~km}$ NARR record was not able to capture that hurricane well.

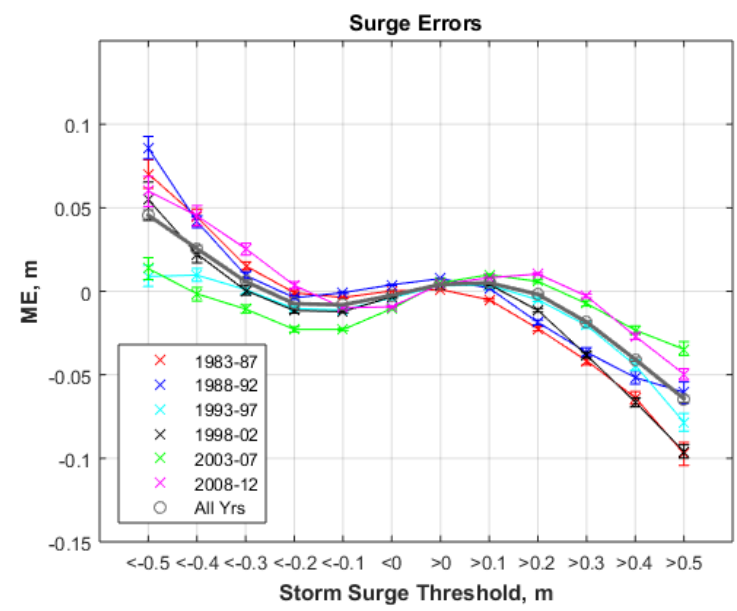

(a)

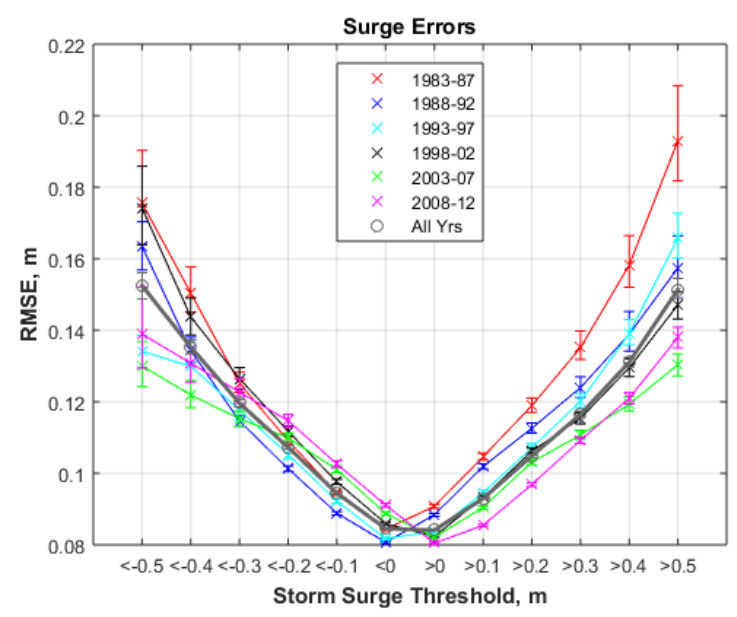

(b)

Figure 9. (a) M.E. and (b) RMSE as a function of storm surge threshold for negative ( - ) and positive (+) surges between different 5-year periods in the NYHOPS hindcast.

The residual water level errors during significant storm surge events appeared to decrease toward the second half of the simulation (Figure 9), even though these later years included some of the highest storm surge peaks in the region's history during Hurricanes Irene and Sandy. It is also important to note however that the NARR-forced NYHOPS still under-predicted Hurricane Sandy's peak surge at The Battery by $\sim 2$ feet, or $\sim 20 \%$ of the observed $\sim 10$ feet surge (Figure 4 ). During the actual event in October 2012 the NYHOPS OFS forecast forced by the deterministic North American Mesoscale (NAM) model at $12 \mathrm{~km}$ resolution under-predicted Sandy's surge at The Battery by approximately 3 feet, while it was within 1 foot when, after the fact, the same model was forced with a more accurate forecast [9] or a high-fidelity reanalysis [10]. 
Another contributing reason to the apparent increase in the model's storm surge simulation skill over time may be due to changes in bathymetry and coastline over time, or other morphodynamic or anthropogenic (targeted channel dredging) changes not accounted for in the NYHOPS historic hindcast: the model's bathymetry is held fixed, and is based on a variety of datasets described in Georgas [14], meant to represent the configuration of the MAB estuaries in the beginning decade of the 21st century. Blumberg and Georgas [13] showed that water levels are quite sensitive to bathymetric uncertainties in the region. Further research is needed in creating a quantitative timeline for such changes, so that future model run versions can account for them.

Table 2 summarizes some skill metrics of the NYHOPS historic hindcast against water temperature and salinity datasets at different estuarine regions, and compares that skill to the overall skill of the NYHOPS OFS forecasts from Georgas [14] and Georgas and Blumberg [15]. The multi-decadal NYHOPS hindcast appears to have comparable or better skill than the validated NYHOPS OFS. Note however that the periods compared and the stations used to aggregate errors are not the same, nor is the forcing methodology: the NYHOPS Hindcast used estimates of daily river flows based on observed hydrographs by USGS and three-hourly heat fluxes based on the $36 \mathrm{~km}$ NARR, while the NYHOPS deterministic OFS used six-hourly NOAA AHPS river discharge forecasts and three-hourly heat fluxes based on the NAM $12 \mathrm{~km}$ forecasts.

Table 2. NYHOPS Hindcast Performance metrics summary for water temperature $(T)$ and salinity $(S)$ at regions within LIS and NYNJH.

\begin{tabular}{|c|c|c|c|c|c|}
\hline Water Temperature & Region & Bias, ${ }^{\circ} \mathrm{C}$ & RMSE, ${ }^{\circ} \mathrm{C}$ & W.I.T & $C F \leq 3{ }^{\circ} \mathrm{C}, \%$ \\
\hline \multirow{3}{*}{$\begin{array}{c}\text { Long Island Sound } \\
\text { CT DEEP } \\
\text { LISS Survey } \\
\end{array}$} & Western Basin & -0.2 & 1.0 & 0.99 & 99 \\
\hline & Central Basin & +0.3 & 1.0 & 0.99 & 99 \\
\hline & Eastern Basin & +0.0 & 0.9 & 1.00 & 100 \\
\hline \multirow{5}{*}{$\begin{array}{l}\text { New York Harbor } \\
\text { NYC DEP } \\
\text { Surface/Bottom data }\end{array}$} & Western LIS & -0.4 & 1.1 & 0.99 & 98 \\
\hline & Upper East River & -0.3 & 1.1 & 0.99 & 99 \\
\hline & Inner Harbor & +0.0 & 1.3 & 0.99 & 98 \\
\hline & Lower NY Bay & +0.1 & 1.3 & 0.99 & 98 \\
\hline & Jamaica Bay & -0.2 & 1.2 & 0.99 & 98 \\
\hline NYHOPS OFS ${ }^{1}$ & NYHOPS $^{2}$ & +0.0 & 1.4 & 0.98 & 95 \\
\hline Salinity & Region & Bias, psu & $R M S E, \mathrm{psu}$ & W.I.S & $C F \leq 3.5 \mathrm{psu}, \%$ \\
\hline \multirow{3}{*}{$\begin{array}{c}\text { Long Island Sound } \\
\text { CT DEEP } \\
\text { LISS Survey } \\
\end{array}$} & Western Basin & +0.1 & 0.5 & 0.91 & 100 \\
\hline & Central Basin & +0.0 & 0.5 & 0.90 & 100 \\
\hline & Eastern Basin & -0.6 & 1.0 & 0.77 & 100 \\
\hline \multirow{5}{*}{$\begin{array}{l}\text { New York Harbor } \\
\text { NYC DEP } \\
\text { Surface/Bottom data }\end{array}$} & Western LIS & +0.5 & 1.3 & 0.77 & 99 \\
\hline & Upper East River & +0.8 & 2.2 & 0.94 & 93 \\
\hline & Inner Harbor & -0.1 & 2.8 & 0.93 & 89 \\
\hline & Lower NY Bay & -0.9 & 2.2 & 0.91 & 91 \\
\hline & Jamaica Bay & +0.0 & 1.8 & 0.71 & 96 \\
\hline NYHOPS OFS ${ }^{1}$ & NYHOPS $^{2}$ & +0.0 & 2.8 & 0.77 & 87 \\
\hline
\end{tabular}

Overall hindcast results are well within NOAA standards and skill metrics for T and S (CF > 90\%; Table 2). Both water temperatures and salinities were very well predicted. Given the greater seasonality in estuarine temperature compared to that of salinity, and the three-hourly meteorological forcing compared to the daily hydrological forcing, the relative RMSE (RMSE divided by the expected range as in Georgas [14]), was higher for salinity than temperature, at an across-station median of $30.9 \%$ versus $4.7 \%$, respectively (Figure 10). Figure 10 highlights spatial differences in model skill (as described by the relative RMSE) within NYNJH, by comparing the quartiles of relative RMSE between the hindcast time series and observed time series at NYC DEP Harbor Survey stations. Even though the Hudson River is one of the most dynamic regions in the estuary, it is also one of the best predicted: 
larger circles in Figure 10 show that the relative RMSE is at its lowest quantile for both $\mathrm{T}$ and $\mathrm{S}$ there. On the other hand, the model had less skill simulating $\mathrm{T}$ and $\mathrm{S}$ within some small tributaries such as Newtown Creek and Flushing Creek in the lower and upper East River, respectively, and several tributaries in Jamaica Bay (Figure 10), especially for salinity. These tributaries receive Storm Water flows and occasional Combined Sewer Overflows from the NYC drainage system, non-point sources that are presently not directly simulated by the NYHOPS model but rather estimated as ungagged watersheds. The model's skill there would potentially benefit greatly through coupling to hydraulic forecast models developed for NYC DEP, although, for a multi-decadal hindcast, changes in the City's drainage system over time may also need to be accounted for: upgrades to two-times dry-weather-flow by the City's treatment plants, sewer separation in some areas, and increase in retention storage in others, for example, affect the spatial and temporal distribution of storm water and combined sewage discharged from the hundreds of the City's interconnected pipes and outfalls.

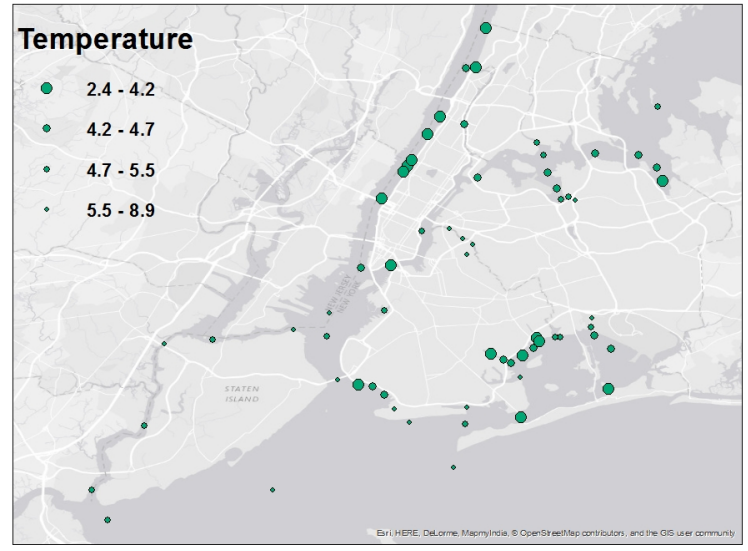

(a)

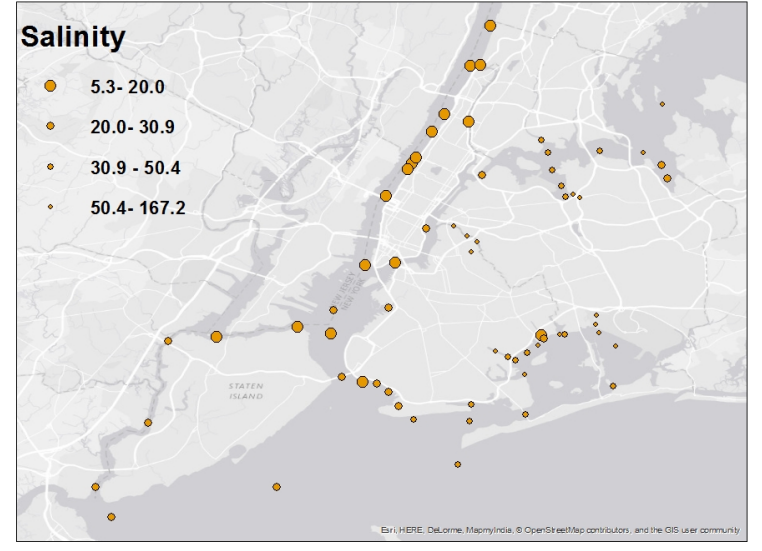

(b)

Figure 10. Quartiles of relative RMSE for (a) water temperature and (b) salinity in the NYNJH for the NYHOPS hindcast at NYC DEP Harbor Survey stations between 1981 and 2012.

The model's dynamics were able to capture more variability than the observation-based MOCHA v2 climatology as evident in relative Brier Skill Scores (BSS) that were positive: 0.48 for temperature and 0.8 for salinity sound-wide. The only exception was for salinity in the Sound's eastern basin, where the period-average relative BSS was -0.29 , indicating that the MOCHA v2 climatology had higher skill than the debiased NYHOPS model there (not shown). Even for that region's salinity, however, the model's total RMSE was only $1 \mathrm{psu}$, of which the remaining bias was $0.6 \mathrm{psu}$, the average index of agreement 0.77 , and the model's results were less than 3.5 psu away from observed more than $99 \%$ of the time. As a comparison, the NOS C.F. standard for simulated salinity is so that errors should be within $3.5 \mathrm{psu}$ for at least $90 \%$ of the time [31]. It is important to note here that results in the Eastern LIS basin as well as the Lower NY Bay appear to have been degraded after debiasing (Table 2). The salinity bias correction in the NYHOPS model is consistent with, though slightly smaller than, earlier models in the region: Both the LISS 2.0 and SWEM models used climatological boundary conditions but subtracted $2.0 \mathrm{psu}$. It is possible that the SODA climatology is biased high for salinity, but the results from the two regions closest to the open boundary in Table 2 may indicate otherwise. Also, like earlier models, the NYHOPS Hindcast does not include the precipitation-evaporation imbalance over the Sound's waters, submarine groundwater discharge, or other aquifer-related freshwater sources. Although these diffuse sources have been estimated to contribute a total freshwater flow over the Sound that is an order of magnitude smaller than the Connecticut River [35,36], they may in any case contribute somewhat to the high-salinity bias in the models. Further research is needed to quantify these contributions, and explore the reason for that consistent bias in models of the region. 
A very important finding of the research is that the NYHOPS model's skill in simulating water temperature, validated against historic data from the LIS bottom trawl survey, did not drift over the years. The error histograms and PDFs included in Figure 11 for four consecutive periods during both the (a) spring and (b) fall survey periods, show that there was no clear indication of an earlier period having greater error than a later one, or vice versa, unlike what was shown earlier for storm surge. A similar analysis against NYC DEP Harbor Survey data in NYNJH for subsequent five-year periods from 1983 to 2012 also did not indicate drift in skill for surface or bottom $T$ nor $S$ (Supplementary Material, Pages 10-18). This is a significant and encouraging finding for multi-decadal model applications used to identify and research climatic trends and causalities. Figure 11 also shows that the median error in simulated bottom temperature in LIS was low for both the spring $\left(+0.1^{\circ} \mathrm{C}\right)$ and the fall $\left(-0.5^{\circ} \mathrm{C}\right)$ surveys, with only few predictions being further than $\pm 1.5^{\circ} \mathrm{C}$ from observed samples.

The lack of model drift was further supported through comparison of the simulated water temperature time series to the one and only long-term water temperature record for Long Island Sound taken at a near-surface location just outside the Millstone Power Plant at Millstone, CT (Figure 12). The central estimate for the linear trend of the observations at Millstone $\left(0.439{ }^{\circ} \mathrm{C} /\right.$ decade $)$ was somewhat higher than the linear trend of the NYHOPS hindcast there $\left(0.313^{\circ} \mathrm{C} /\right.$ decade), and the simulated annual range was somewhat higher than observed (Figure 12), however the two trends were not different at the $95 \%$ confidence level. Figure 12 shows that water temperature was simulated very well throughout the hindcast period. It also shows clearly that temperatures have been increasing at the site and that 2012 was the warmest year in both the simulated and observed record.

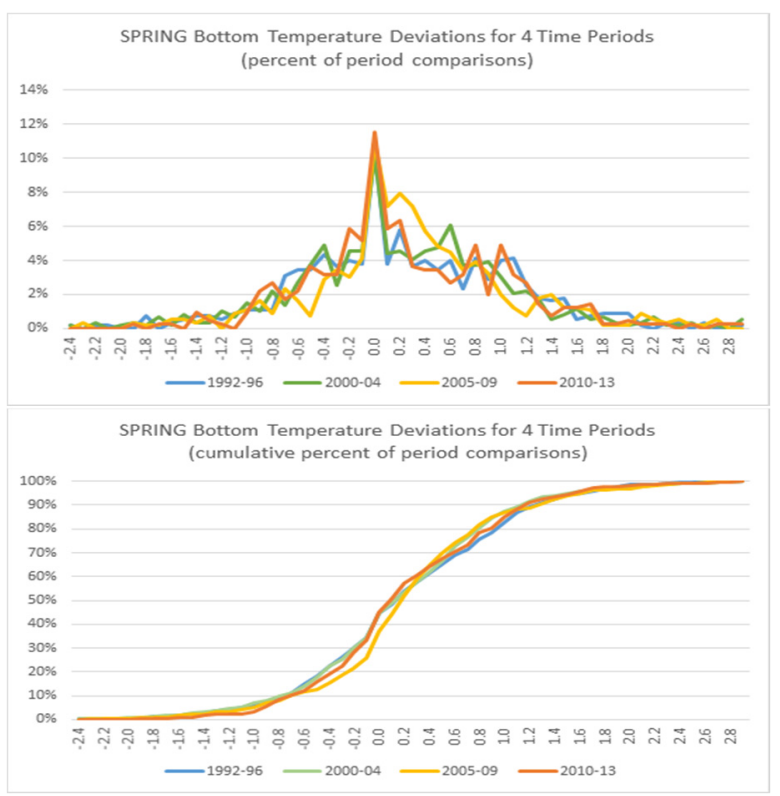

(a)

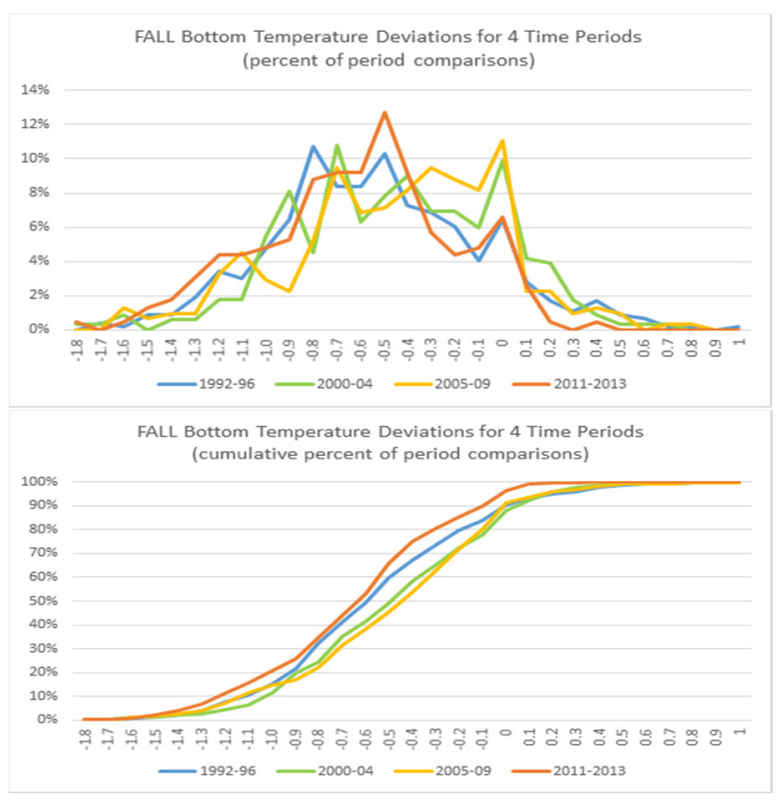

(b)

Figure 11. Error histograms (top) and probability density functions (bottom) between NYHOPS Hindcast bottom temperature results and LIS Trawl Survey bottom temperature samples for four subsequent spring (a) and fall (b) survey periods from 1992 to 2013. 

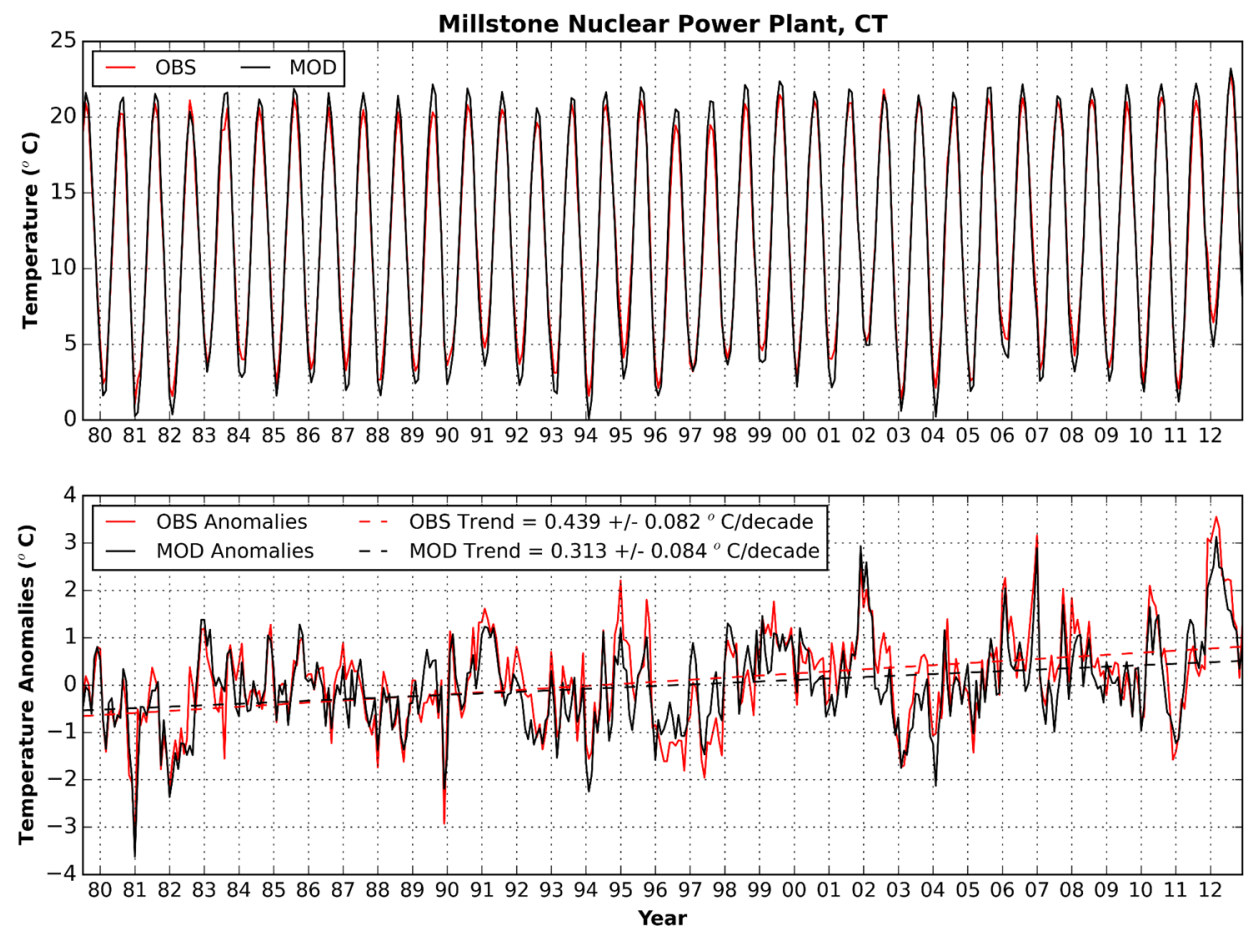

Figure 12. Monthly mean water temperature (top) and water temperature anomaly (bottom; after removal of seasonal signal) time series near the Millstone Nuclear Power Plant outfall location at Millstone, CT, as observed (OBS), and simulated (MOD).

NYHOPS model results were then used to quantify linear, water temperature, salinity, and stratification trends for LIS in the hindcast period between 1981 and 2013. Spatially averaged trends over the three Long Island Sound management basins (east, central, west), and the Sound as a whole are shown in Figure 13, with confidence intervals, while the spatial variation on the NYHOPS grid cell level is seen in Figure 14. Statistically significant warming and freshening trends (Figure 13), non-stationary trends in volumetric fluxes across the western and eastern basins of the Sound (Figure 15), and an associated statistically significant increase in stratification (Figures 13 and 14) have all occurred within the hindcast period. Based on the NYHOPS hindcast, in the Long Island Sound basin, surface air temperatures, contributing river temperatures, and receiving LIS-basin-wide water temperatures $\left(0.34 \pm 0.08^{\circ} \mathrm{C}\right.$ per decade) have all seen significant increases between 1981 and 2013, more so on the shallower north shore and western Sound than the south shore similar to [37]. The basin wide average is comparable to the $0.30{ }^{\circ} \mathrm{C}$ per decade rate reported for SST at the Gulf of Maine [3]. The increase in major freshwater rivers mentioned in Section 2 may have led to the Sound overall becoming somewhat fresher (a statistically significant trend of $0.12 \pm 0.05 \mathrm{psu} / \mathrm{decade}$ ), especially near river mouths at the surface (Figure 14), increasing stratification and changing long-term volumetric transport fluxes in the basin in a statistically significant, nonstationary way (Figure 15). Further research is needed to deduce whether these trends are expected to continue into the future. 


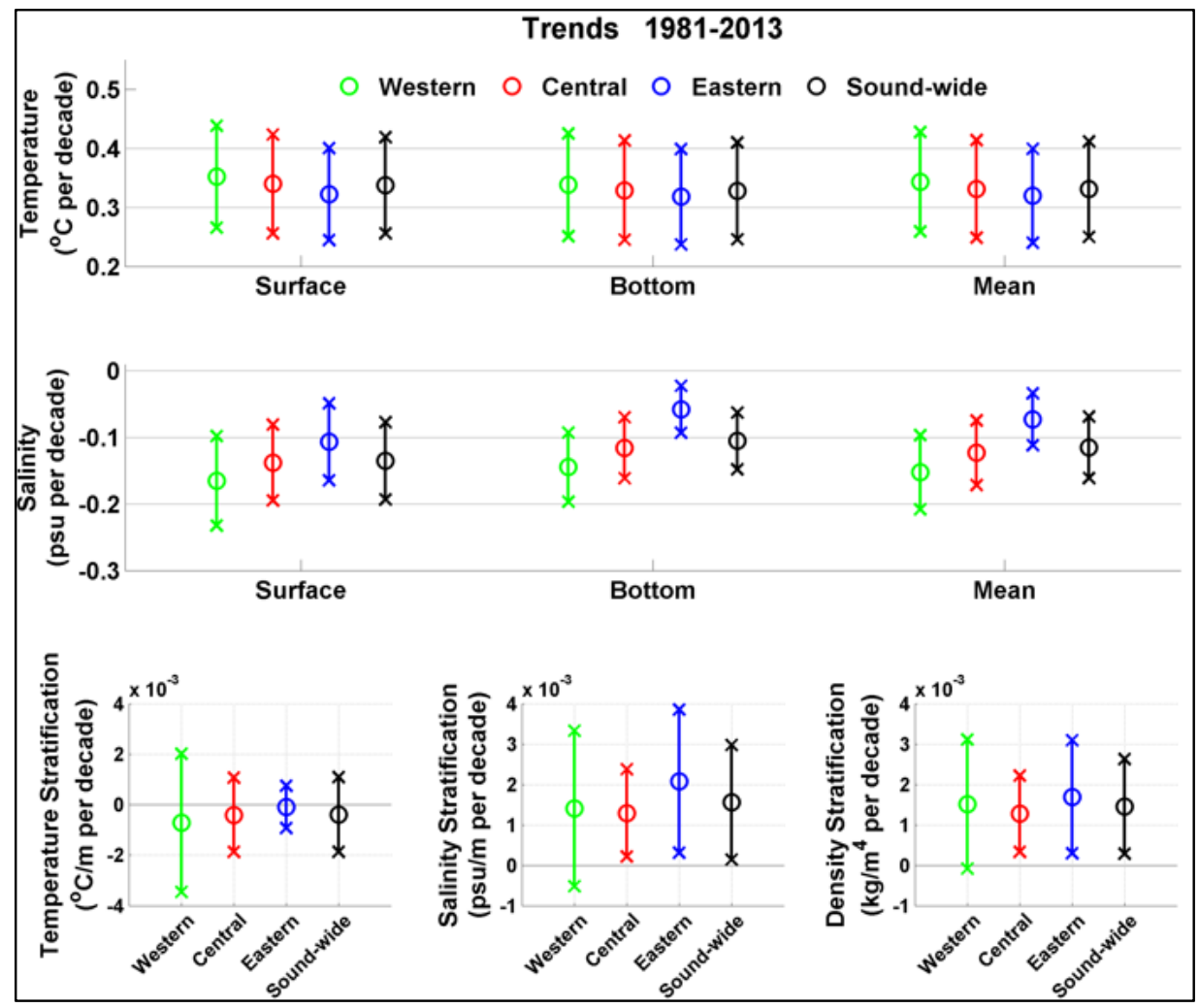

Figure 13. Decadal-averaged linear trends in water temperature (top), salinity (middle), and stratification (bottom), for the three LIS basins, and the whole Sound within the 1981-2013 NYHOPS Hindcast period. Circles show central estimates while vertical bars show the $95 \%$ confidence intervals.

\section{Temperature}

Surface $\left({ }^{\circ} \mathrm{C}\right.$ per decade)

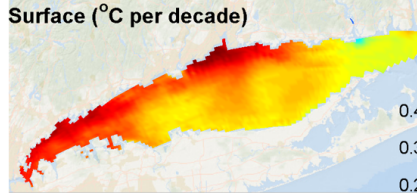

Bottom ( ${ }^{\circ} \mathrm{C}$ per decade)

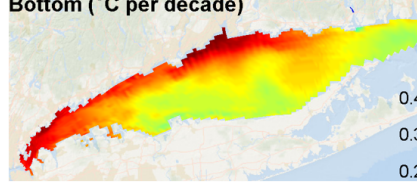

Salinity

Surface (psu per decade)

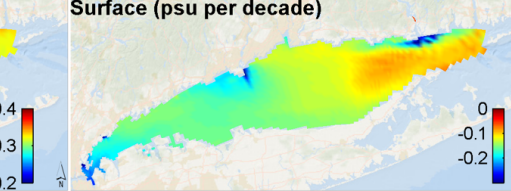

Bottom (psu per decade)

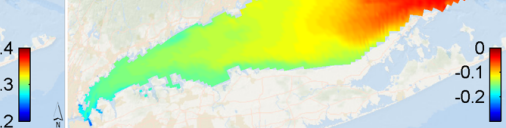

Mean (psu per decade)

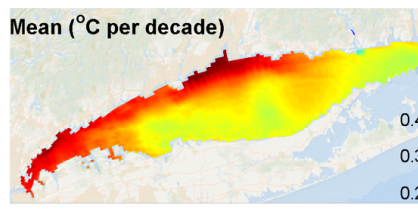

Stratification $\left({ }^{\circ} \mathrm{C} / \mathrm{m}\right.$ per decade)

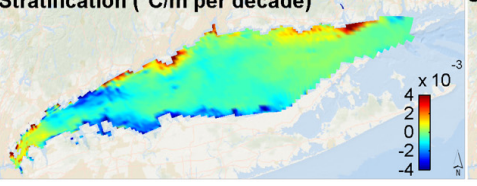

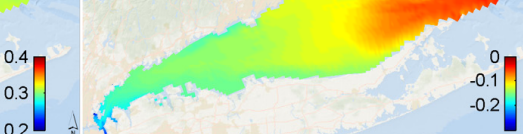

Stratification (psu/m per decade)
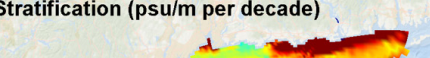

Density

Surface $\left(\mathrm{kg} / \mathrm{m}^{3}\right.$ per decade)

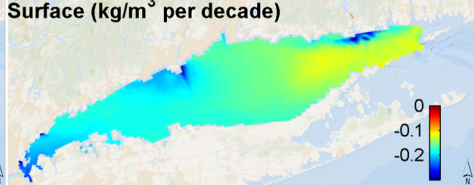

Bottom ( $\mathrm{kg} / \mathrm{m}^{3}$ per decade)

-0.1
-0.2

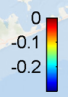

Figure 14. Spatial map of locally computed decadal-averaged linear trends in water temperature (left), salinity (center), density (right), and stratification (bottom) within the 1981-2013 NYHOPS Hindcast period. Surface and bottom are from the surface-most and bottom-most NYHOPS cells, mean is for the vertically averaged trends, and stratification is computed from surface to local bottom. 


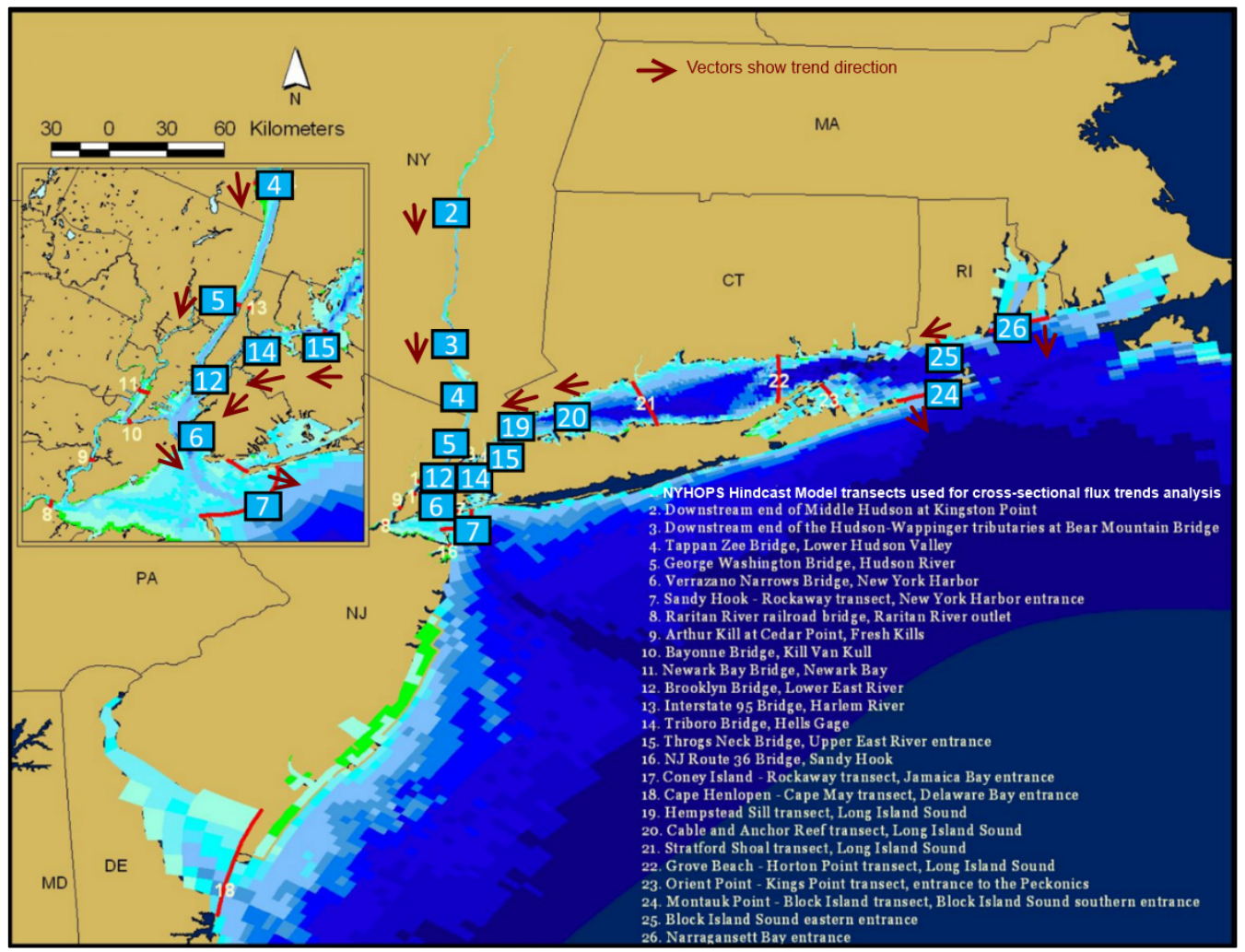

Figure 15. NYHOPS model transects across which linear trends in volumetric cross-channel transport were quantified. Transects for which statistically significant trends in volumetric fluxes between 1981 and 2013 were calculated (at the 95\% confidence level) are highlighted with blue squares.

\section{Conclusions}

The NYHOPS model's application to hindcast storm surge and 3D water temperature and salinity conditions in its region over three-and-a-half decades was validated against observations from multiple agencies, as well as climatology: the average index of agreement for storm surge alone was $0.93(9 \mathrm{~cm}$ RMSE, $90 \%$ of errors less than $15 \mathrm{~cm})$; for water temperature, it was $0.99\left(1.1^{\circ} \mathrm{C} R M S E, 99 \%\right.$ of errors less than $\left.3{ }^{\circ} \mathrm{C}\right)$; and for salinity, it was 0.86 (1.8 psu RMSE, $96 \%$ of errors less than $\left.3.5 \mathrm{psu}\right)$. The model's skill in simulating bottom water temperature, validated against historic data from the Long Island Sound bottom trawl survey, did not drift over the years, a significant and encouraging finding for multi-decadal model applications used to identify climatic trends. However, the validation revealed residual biases in some areas, including small tributaries that receive urban discharges from the NYC drainage network. With regard to the validation of storm surge at coastal stations, both the considerable strengths and remaining limitations of the use of NARR to force such a model application were discussed.

Through the comprehensively forced, and herein extensively validated, multi-decadal simulation for Long Island Sound's physical environment performed using Stevens Institute of Technology's NYHOPS hindcast model, temperature increases in Long Island Sound over the past three-and-a-half decades have been confirmed and have been found to be statistically significant. The linear trends have also been found to be quite high $\left(0.34 \pm 0.08{ }^{\circ} \mathrm{C}\right.$ per decade) and comparable to ones in the Gulf of Maine [3]. Further research is needed in identifying the cause for this increase in temperatures. Source allocation and further sensitivity runs using the NYHOPS model may aid in testing hypotheses in the future.

After extensive model validation and debiasing, an online THREDDS Data Server (http://colossus.dl.stevens-tech.edu/thredds/catalog.html) was set up to serve the NYHOPS model's 
results in NetCDF format over the web using the OPENDAP protocol, enabling similar analyses through open access to daily averaged or monthly averaged time series for all the gridded hindcast physical variables in or over the NYHOPS region that includes NYNJH and LIS.

Fisheries management has traditionally sought to reduce harvesting levels in response to low stock biomass, in its goal to maintain long-term fishery productivity [38]. More recently, accounting for non-stationary environmental forcing has started being considered in stock assessment and management ([39], pp. 131-147) with the realization that a failure to account for shifts in climate that can alter population dynamics can lead to stock collapse as with the Gulf of Maine cod fishery [3]. This progress has been facilitated by new population dynamics models that consider temperature-dependencies and an improved understanding in climate-fisheries teleconnections brought about through advances in environmental modeling.

NYHOPS Hindcast results are in demand to support this kind of fisheries research through coupling to habitat suitability indices, population models, water quality models, or to provide boundary conditions to higher resolution embayment or tributary circulation models. The datasets are also presently used to inform ongoing research in climate teleconnections and ecosystem change through exploratory statistical analyses linking regional fisheries abundance to global climate indices. The authors are encouraged by the early interest in these datasets.

Simulated climatologies (mean simulated climate conditions averaged over the three decades of the NYHOPS hindcast period) for two- and three-dimensional fields such as water temperatures and salinities, were also generated, and included in THREDDS. Included on the same THREDDS server is a "daily anomaly" dataset, comparing the latest operational forecast of the NYHOPS OFS model to the 1981-2013 debiased daily climatology, so that interested parties can see how different yesterday and the next three days are predicted to be from the climatological average, enabling near-term tracking of anomalous patterns in Long Island Sound. Fish-surveying strategies may also be improved through the use of the NYHOPS model forecasts: NYSDEC and NMFS routinely already use the model's predictions for adaptive sampling in the Hudson River estuary and the Mid-Atlantic Bight Apex. Visualization is easy with off-the-shelf free software, such as NASA's Panoply, accessing the datasets over the web.

Supplementary Materials: The following are available online at www.mdpi.com/2077-1312/4/3/48/s1, Comprehensive Validation and LIS Trend Presentation.

Acknowledgments: Financial support was provided by the US EPA Long Island Sound Study and NY and CT Sea Grants through the project R/CE-33-NYCT. Long-term NYHOPS model support has been provided through the NOAA Integrated Ocean Observing System program and many other projects. The authors appreciate the help of CT DEEP personnel and Nicholas Kim from HDR. Inc. in providing CT DEEP and NYC DEP temperature and salinity observations used in this work.

Author Contributions: Nickitas Georgas, Penny Howell, and Vince Saba conceived and designed the experiments. Yu Jiang, Larry Yin, and Nickitas Georgas performed the experiments. Larry Yin, Yifan Wang, Penny Howell, Yu Jiang, Bin Wen, and Nickitas Georgas analyzed the data; Philip Orton contributed the SNAP grid and provided model input guidance; Nickitas Georgas wrote the paper.

Conflicts of Interest: The authors declare no conflict of interest. The founding sponsors had no role in the design of the study; in the collection, analyses, or interpretation of data; in the writing of the manuscript, and in the decision to publish the results.

\section{References}

1. NCDC. Climate at a Glance. Time Series. Available online: http://www.ncdc.noaa.gov/cag/time-series/ (accessed on 15 July 2016).

2. United Nations. Paris Agreement. United Nations Treaty Collection. Available online: https://treaties. un.org/pages $/$ ViewDetails.aspx?src=TREATY\&mtdsg_no=XXVII-7-d\&chapter=27\&lang=en (accessed on 15 July 2016).

3. Pershing, A.; Alexander, M.A.; Hernandez, C.M.; Kerr, L.A.; le Bris, A.; Mills, K.E.; Nye, J.A.; Record, N.R.; Scannell, H.A.; Scott, J.D.; et al. Slow Adaptation in the Face of Rapid Warming Leads to Collapse of the Gulf of Maine Cod Fishery. Science 2015. [CrossRef] [PubMed] 
4. Dominion Resource Services. Monitoring the Marine Environment of Long Island Sound at Millstone Power Station. Annual Report 2002. Millstone Environmental Laboratory, April 2003. Available online: http:/ / pbadupws.nrc.gov/docs/ML0409/ML040930039.pdf (accessed on 12 August 2016).

5. Nye, J.A.; Link, J.S.; Hare, J.A.; Overholtz, W.J. Changing spatial distribution of fish stocks in relation to climate and population size on the Northeast United States continental shelf. Mar. Ecol. Prog. Ser. 2009, 393, 111-129. [CrossRef]

6. Howell, P.; Auster, P. Phase shift in an estuarine finfish community associated with warming temperatures. Mar. Coast. Fish. Dyn. Manag. Ecosyst. Sci. 2012, 4, 481-495. [CrossRef]

7. Kleisner, K.M.; Fogarty, M.J.; McGee, S.; Barnett, A.; Fratantoni, P.; Greene, J.; Hare, J.A.; Lucey, S.M.; McGuire, C.; Odell, J.; et al. The Effects of Sub-Regional Climate Velocity on the Distribution and Spatial Extent of Marine Species Assemblages. PLoS ONE 2016. [CrossRef] [PubMed]

8. Georgas, N.; Howell, P.; Saba, V.; Schulte, J.; Blumberg, A.F.; Orton, P.; Yin, L.; Jiang, Y.; Wang, Y. Analyzing History to Project and Manage the Future: Simulating the Effects of Climate on Long Island Sound's Physical Environment and Living Marine Resources. Final Report. NOAA Sea Grant Publications, Long Island Sound Study, 2016. Available online: http:/ /longislandsoundstudy.net/wp-content/uploads/2013/08/Georgas-etal-R-CE-33-NYCT-CR-Final-Report.pdf (accessed on 15 July 2016).

9. Georgas, N.; Orton, P.; Blumberg, A.F.; Cohen, L.; Zarrilli, D.; Yin, L. The impact of tidal phase on Hurricane Sandy's flooding around New York City and Long Island Sound. J. Extreme Events 2014. [CrossRef]

10. Marsooli, R.; Orton, P.M.; Georgas, N.; Blumberg, A.F. Three-dimensional hydrodynamic modeling of coastal flood mitigation by wetlands. Coast. Eng. 2016, 111, 83-94. [CrossRef]

11. Georgas, N.; Blumberg, A.F.; Herrington, T.; Wakeman, T.; Saleh, F.; Runnels, D.; Jordi, A.; Ying, K.; Yin, L.; Ramaswamy, V.; et al. The Stevens Flood Advisory System: Operational H3-E flood forecasts for the greater New York/New Jersey metropolitan region. Int. J. Saf. Secur. Eng. 2016, 6, 1-15.

12. Georgas, N.; Blumberg, A.F.; Herrington, T. An operational coastal wave forecasting model for New Jersey and long Island waters. Shore Beach 2007, 75, 30-35.

13. Blumberg, A.F.; Georgas, N. Quantifying Uncertainty in Estuarine and Coastal Ocean Circulation Modeling. J. Hydraul. Eng. 2008, 134, 403-415. [CrossRef]

14. Georgas, N. Establishing Confidence in Marine Forecast Systems: The Design of a High Fidelity Marine Forecast Model for the NY/NJ Harbor Estuary and Its Adjoining Coastal Waters. Ph.D. Thesis, Stevens Institute of Technology, Hoboken, NJ, USA, August 2010; p. 272. Available online: http:/ /web.stevens.edu/ ses/documents/fileadmin/documents/pdf/PhD-dissertation_signed-o.pdf (accessed on 15 July 2016).

15. Georgas, N.; Blumberg, A.F. Establishing confidence in marine forecast systems: The design and skill assessment of the New York harbor observation and prediction system, Version 3 (NYHOPS v3). In Proceedings of the 11th International Conference in Estuarine and Coastal Modeling (ECM11), Seattle, WA, USA, 4-6 November 2010; pp. 660-685.

16. DiLiberto, T.; Colle, B.A.; Georgas, N.; Blumberg, A.F.; Taylor, A.A. Verification of a Multi-Model Storm Surge Ensemble Around New York City and Long Island During the Cool Season. Weather Forecast. 2011, 26, 922-939. [CrossRef]

17. Orton, P.M.; Georgas, N.; Blumberg, A.F.; Pullen, J. Detailed modeling of recent severe storm tides in estuaries of the New York City region. J. Geophys. Res. 2012, 117, C09030. [CrossRef]

18. Wilkin, J.L.; Hunter, E.J. An assessment of the skill of real-time models of Mid-Atlantic Bight continental shelf circulation. J. Geophys. Res. Oceans 2013, 118, 2919-2933. [CrossRef]

19. Blumberg, A.F.; Georgas, N.; Herrington, T.; Yin, L. Street Scale Modeling of Storm Surge Inundation along the New Jersey Hudson River Waterfront. J. Atmos. Ocean. Technol. 2015, 32, 1486-1497. [CrossRef]

20. Blumberg, A.F.; Mellor, G.L. A description of a three dimensional coastal ocean circulation model. In Three-Dimensional Coastal Ocean Models; Heaps, N.S., Ed.; American Geophysical Union: Washington, DC, USA, 1987; Volume 4, pp. 1-16.

21. Mesinger, F.; Dimego, G.; Kalnay, E.; Mitchell, K.; Shafran, P.C.; Ebisuzaki, W.; Jovic, D.; Woollen, J.; Rogers, E.; Berbery, E.H.; et al. North American Regional Reanalysis. Bull. Am. Meteorol. Soc. 2006, 87, 343-360. [CrossRef]

22. Choi, W.; Keuser, A.; Becker, S. Identification of mid-latitudinal regional and urban temperature variabilities based on regional reanalysis data. Theor. Appl. Climatol. 2012, 107, 87-98. [CrossRef] 
23. Bhushan, S.; Blumberg, A.F.; Georgas, N. Comparisons of NYHOPS Hydrodynamic Model SST Predictions with Satellite Observations in the Hudson River Tidal, Estuarine and Coastal Plume Region. In Proceedings of the 11th International Conference in Estuarine and Coastal Modeling (ECM11), Seattle, WA, USA, 4-6 November 2010; pp. 11-26.

24. Taylor, P.K.; Yelland, M.A. The dependence of sea surface roughness on the height and steepness of the waves. J. Phys. Oceanogr. 2001, 31, 572-590.

25. Georgas, N. Analyzing History to Project and Manage the Future: Simulating the Effects of Climate on Long Island Sound's Physical Environment and Living Marine Resources. Supplementary Matter to Year 1 Report. Available online: http://www.stevens.edu/ses/documents/fileadmin/documents/pdf/R-CE-33-NYCT\% 20PR1\%20supporting\%20year\%201\%20PR.pdf (accessed on 15 July 2016).

26. Carton, J.A.; Giese, B.S. A reanalysis of ocean climate using Simple Ocean Data Assimilation (SODA). Mon. Weather Rev. 2008, 136, 2999-3017. [CrossRef]

27. Chassignet, E.P.; Hurlburt, H.E.; Metzger, E.J.; Smedstad, O.M.; Cummings, J.A.; Halliwell, G.R.; Bleck, R.; Baraille, R.; Wallcraft, A.J.; Lozano, C.; et al. US GODAE: Global Ocean Prediction with the HYbrid Coordinate Ocean Model (HYCOM). Oceanography 2009, 22, 64-75. [CrossRef]

28. Seekell, D.A.; Pace, M.L. Climate change drives warming in the Hudson River estuary, New York (USA). J. Environ. Monit. 2011, 13, 2321-2327. [CrossRef] [PubMed]

29. Kaushal, S.S.; Likens, G.E.; Jaworski, N.A.; Pace, M.L.; Sides, A.M.; Seekell, D.; Wingate, R.L. Rising stream and river temperatures in the United States. Front. Ecol. Environ. 2010, 8, 461-466. [CrossRef]

30. Fleming, N.E.; Wilkin, J. MOCHA: A 3-D climatology of the temperature and salinity of the Mid Atlantic Bight. Eos Trans. AGU 2010, 91, PO35G-08. Available online: http:/ / abstractsearch.agu.org/meetings/2010/OS/ PO35G-08.html (accessed on 15 August 2016).

31. NOAA Technical Report NOS CS 17. NOS Standards for Evaluating Operational Nowcast and Forecast Hydrodynamic Model Systems. Available online: www.nauticalcharts.noaa.gov/csdl/publications/TR_ NOS-CS17_FY03_Hess_OFS-Standards.pdf (accessed on 12 August 2016).

32. Willmott, C.J. On the validation of models. Phys. Geogr. 1981, 2, 184-194.

33. Taylor, K.E. Summarizing multiple aspects of model performance in a single diagram. J. Geophys. Res. 2001, 106, 7183-7192. [CrossRef]

34. Von Storch, H.; Zwiers, F.W. Statistical Analysis in Climate Research; Cambridge University Press: Cambridge, UK, 1999; p. 494.

35. O'Donnell, J.; Wilson, R.E.; Lwiza, K.; Whitney, M.M.; Bohlen, W.F.; Codiga, D.; Fribance, D.B.; Fake, T.; Bowman, M.; Varekamp, J. The Physical Oceanography of Long Island Sound. In Long Island Sound. Prospects for the Urban Sea; Springer: New York, NY, USA, 2014; pp. 79-158.

36. Garcia-Orellana, J.; Cochran, J.K.; Bokuniewicz, H.; Daniel, J.W.R.; Rodellas, V.; Heilbrun, C. Evaluation of ${ }^{224} \mathrm{Ra}$ as a tracer for submarine groundwater discharge in Long Island Sound (NY). Geochim. Cosmochim. Acta 2014, 141, 314-330. [CrossRef]

37. Lee, Y.J.; Lwiza, K. Interannual variability of temperature and salinity in shallow water: Long Island Sound, New York. J. Geophys. Res. 2005, 110, C09022. [CrossRef]

38. Mahon, R.; McConney, P.; Roy, R.N. Governing fisheries as complex adaptive systems. Mar. Policy 2008, 32, 104-112. [CrossRef]

39. Northeast Fisheries Science Center Reference Document 14-04. 58th Northeast Regional Stock Assessment Workshop (58th SAW) Assessment Report. Available online: http://www.nefsc.noaa.gov/publications/crd/ crd1404/crd1404.pdf (accessed on 15 August 2016).

(C) 2016 by the authors; licensee MDPI, Basel, Switzerland. This article is an open access article distributed under the terms and conditions of the Creative Commons Attribution (CC-BY) license (http://creativecommons.org/licenses/by/4.0/). 